\title{
The importance of situated language use for aphasia rehabilitation
}

\author{
Doedens, W.J. \& Meteyard, L. ${ }^{1}$ \\ School of Psychology and Clinical Language Sciences, \\ University of Reading, United Kingdom
}

\begin{abstract}
There is a growing realization that the traditional approach to studying language, i.e. as a decontextualized, linguistic phenomenon, does not allow us to fully understand communication in the real world. By studying the way people process words and sentences in isolation, a wealth of variables that play a role in naturalistic communication are missed. In the study of aphasia, a language impairment caused by acquired brain damage such as stroke, a thorough understanding of the mechanisms of naturalistic communication is imperative, as this is the behaviour therapy aims to improve. The field of aphasiology currently lacks a comprehensive, theoretically founded definition of communication. This lack of understanding, we will argue, makes it nearly impossible to accurately describe a person's level of communicative ability in everyday life as well as to predict with certainty what kind of intervention will lead to a change at the level of communication. In this article we propose a model of situated language use borrowed from sociology, psychology, communication sciences and psycholinguistics, which covers both internal (e.g. individual) and external (e.g. environmental) factors that influence communication, including the traditional linguistic skills that have been extensively researched in the past. The model defines language use as: (1) interactive, (2) multimodal, and (3) based on context (common ground). An extensive review of existing research on each component of the model in non-brain damaged adults and people with aphasia is provided. The consequences of adopting this approach to diagnosis and therapy for aphasia are discussed. The aim of this article is to encourage a more systematic approach to the study of situated language use in aphasia.
\end{abstract}

Keywords: Functional communication, aphasia, multimodal, interactive, common ground, functional communication

\footnotetext{
${ }^{1}$ Corresponding author: Ms W.J. Doedens, University of Reading, Whiteknights, RG6 6AL, United Kingdom. E-mail address: w.j.doedens@pgr.reading.ac.uk

Preprint submitted to Journal of $L^{A} T_{E} X$ Templates

July 31, 2018
} 


\section{1. Introduction}

Decades of language research have predominantly focused on the processing and acquisition of spoken and written words and sentences (Vigliocco et al., 2014). Most of this research has studied language in isolation: words and sentences are presented aurally or visually in the lab, in a highly controlled environment. These studies have greatly contributed to our current knowledge and understanding of language processing as a cognitive phenomenon. In parallel, cognitive neuropsychological language processing models first developed in the 1950s have led to detailed insights into the variety of linguistic variables that are of importance when processing linguistic information, „such as phonological complexity, age of acquisition, concreteness (e.g. Levelt et al., 1999, Balota

et al. 2007) and syntactic complexity (e.g. Brown, 1999). The question arises, however, to what extent do these findings translate to language as it is used in the real world. There is increasing evidence that language is processed differently in its rich, dynamic natural environment, i.e. 'in situ' (Clark, 2018a), compared to the well-controlled laboratory environment, where linguistic stimuli are presented without context (Willems, 2015), i.e. 'in vacuo' (Clark, 2018b). There is a growing understanding that the traditional approach to the study of language in vacuo, i.e. studying single words and sentences in isolation, does not necessarily tell us something about actual language use in the real world (Vigliocco et al., 2014, Clark, 1996, Willems, 2015; Hasson et al. 2018, Barnes \& Bloch, 2018). The study of natural language use poses several challenges and requires (1) a clear definition of what language use entails and (2) a method that provides the most reliable and ecologically valid results possible.

These issues have reached a critical point in the study of aphasia, a language impairment caused by acquired brain damage such as stroke. Language processing approaches to aphasia emerged in the 1970s, and have since provided rich detail on the variation and complexity of language impairments seen in this condition. Notably, measures of language impairment borrowed heavily from studies in psycholinguistics, using decontextualized tasks such as picture naming, repetition, single word and single sentence comprehension. These measures give a linguistically well-define profile of impairment, but lack detail on how the language impairment manifests in 'real world' communication. In the aphasia literature, real-world communication is referred to as functional communication. The overarching aim of speech and language therapy (SLT) is for 
People With Aphasia (PWA) to communicate as effectively as possible in everyday life - i.e. to see improvements in their functional communication (Thompson et al. 2008). Systematic reviews have shown overall moderate effectiveness of SLT intervention compared to no intervention on functional communication (Brady et al. 2016), but it has proven difficult find consistent, reliable, long term generalization effects from SLT therapy to meaningful measures such as language use in everyday Westbury, 2011, Kasselimis et al., 2017), but it is not sufficient to describe or predict a person's ability to communicate. In fact, there is a general agreement in the aphasia literature that everyday communication represents an entirely different process compared to the decontextualized tasks that are traditionally used to measure linguistic functioning (Beeke et al., 2011). Knowing that communication requires more than just linguistic skills, it should be relatively unsurprising that interventions based on decontextualized, linguistic tasks such as picture-naming should produce only small, if any improvements at the level of everyday communication. The assumption that there is no one-to-one mapping between linguistic skills and language use 'in situ' is also in line with the finding that measures of linguistic impairment cannot fully predict how PWA will use language in everyday life (Holland, 1982, Armstrong et al., 2011; Beeke et al., 2007; Davidson et al., 2008 Kolk \& Heeschen, 1992; Wilkinson, 1995). The lack of consensus on what skills and behaviours are required for functional communication is also reflected in the numerous instruments that are currently used to measure the use of language in everyday life (Brady et al., 2016, Barnes \& Bloch 2018). These numerous approaches and measures mean that the literature lacks consistency in for functional communication or complete robust meta-analyses. Furthermore, it makes it nearly impossible to say with certainty what kind of intervention will lead to a change at the level of communication. Despite these crucial limitations, no attempt has yet been made to theoretically and systematically scrutinize the concept of communication with as much vigour as we have scrutinized 
with a lack of understanding of what communication entails and of what skills are required to communicate efficiently.

The aim of this article is to propose a specific and measurable definition of situated language use, based on the now extensive literature in the fields of psychology, communication sciences, of instruments have been developed. These can be grouped according to the type of instrument that is used to capture functional communication in PWA: (1) standardized tests, (2) observational profiles rated by the clinician; (3) observational profiles rated by a proxy or the client and (4) linguistic profiles of connected speech. The most relevant and recently developed instruments will linguistics, psycholinguistics and sociology with healthy adults as well as PWA. The model aims to cover both internal (e.g. individual skills) and external (e.g. environmental) factors that influence a person's ability to communicate efficiently, thereby moving away from the idea that communicative ability can be boiled down to a single number Barnes \& Bloch, 2018, The article will be structured as follows: a review of how language use is defined in the field of aphasiology, focusing on the instruments that are used to measure situated language use in aphasia. This is followed by a description of the proposed model and a review of the literature of situated language use in healthy adults and PWA. Based on these findings, the instruments used to measure language use in aphasia are compared to the newly proposed model. Finally, the model will be used to provide a set of fruitful avenues for further research, including key internal and external factors and empirical measures. By proposing a theoretically founded model of situated language use, the authors hope to encourage a more structured and systematic approach to this field of study. Consequently, the field can get a better grasp on the factors that influence language as it is used in its natural environment. Only then will it become feasible to study the relationship and interaction between linguistic impairments and communication difficulties.

\section{Current approaches to measuring communication in aphasiology}

In the field of aphasiology, the term 'functional communication' is most often used to refer to the ability to communicate, or use language, in everyday life. The term lacks a clear definition, however, and has subsequently been used in a wide variety of ways in the literature, depending on the purpose of the interpretation and the conceptual framework the definition is embedded within (Elman \& Bernstein-Ellis, 1995). As a result of these different interpretations, a large number be briefly discussed and critiqued below, to give an idea of the breath of approaches and definitions 
of functional communication in the field of aphasiology (please refer to Table 1 for a summary of all the instruments reviewed). For a more extensive discussion of these and additional measures, please see Manochiopinig et al. (1992), Spreen \& Risser (2003), Patterson \& Chapey (2008), Holland \& Thompson (1998). Frattali \& Fromm, 1999), Amsterdam-Nijmegen Everyday Language Test (ANELT; Blomert, Kean, Koster \& Schokker, 1994) and the Scenario Test van der Meulen, van de Sandt-Koenderman, Duivenvoorden \& Ribbers, 2010) quantify functional communication as the degree of communicative success in hypothetical, simulated everyday situations, elicited by pictures and questions, or role play with the clinician (i.e. visiting the doctor's office or getting a shirt back from the dry cleaners). The CADL-2 has been criticized for focusing on the transmission of a message by the PWA, without taking into account the interactive aspect of everyday communication (Ramsberger \& Rende, 2002 van der Meulen et al. 2010): PWA are presented with a situation and asked to provide a fitting response. While the ANELT and the Scenario Test do assess interaction through role play, the ANELT only measures verbal exchanges and does not take into account the non-verbal aspects of interaction (van der Meulen et al., 2010). The use of role play, or simulating everyday communication in a clinical setting, has been suggested to make additional cognitive demands, that is often not required in real-life situations, such as pretending to be somewhere you're not (Ramsberger, 1994,

Wirz et al. 1990). In short, the standardized tests attempt to capture functional communication through the simulation of a sample of possible real-life encounters, and measuring the degree of success in transmitting a message in those situations.

\subsection{Observational profiles (clinician rated)}

The second category contains observational profiles that are rated by the clinician. With the Functional Communication Profile (FCP), Sarno (1969) was the first to publish a measure of functional communication, defined as a test that concerns itself with 'how' the PWA communicates, as opposed to 'what' the PWA communicates, with the aim of quantifying the communicative behaviour of the PWA in interaction. Sarno developed a list of communicative behaviours across different categories (reading, understanding, speaking, gesturing, etc), such as 'reading street signs' 
Standardized tests

Observational profiles (clinician rated)

Observational profiles (client or proxy rated) connected speech
- Communicative Abilities in Daily Living 2 (CADL-2; Holland, Frattali \& Fromm, 1999,

- Amsterdam-Nijmegen Everyday Language Test (ANELT; Blomert, Kean, Koster \& Schokker, 1994)

- Scenario Test (van der Meulen, van de Sandt-Koenderman, Duivenvoorden \& Ribbers, 2010)

- Functional Communication Profile (FCP; Sarno, 1969

- Revised Edinburgh Functional Communication Profile (Wirz, Skinner \& Dean, 1990

- American-Speech-Language-Hearing Association Function Assessment for Communicative Skills in Adults (ASHA FACS; Frattali, Thompson, Holland, Wohl \& Ferketic, 1995,

- Communicative Effectiveness Index (CETI; Lomas, Pickard, Bester, Elbard, Finlayson \& Zoghaib, 1989,

- Assessment of Communicative Effectiveness in Severe Aphasia (ACESA; Cunningham, Farrow, Davies \& Lincoln, 1995,

- Functional Outcome Questionnaire for Aphasia (FOQ-A; Glueckauf, Blonder, Ecklund-Johnson, Maher, Crosson \& Gonzalez-Rothi, 2003,

- Communicative Activity Log (CAL; Pulvermuller \& Berthier, 2008),

- Communication Outcome after Stroke, client and carer version (COAST and carer COAST; Long, Hesketh \& Bowen, 2009, Long, Hesketh, Paszek, Booth \& Bowen, 2008,

- Aphasia Communication Outcome Measure (ACOM; Doyle, Hula, Hula, Ross, Wambaugh, Schumacher \& Roehrig, 2012.

- Correct Information Unit Analysis (CIU; Nicholas \& Brookshire, 1993

- Information Units (IU; McNeil, Doyle, Fossett, Park \& Goda, 2001,

- Pragmatic Protocol (PPL; Prutting \& Kirchner, 1987,

- Conversation Analysis (CA; Beeke, Maxim \& Wilkinson, 2007) 
or 'speaking on the telephone' that could be ticked off as executed by the PWA or not, including a judgement of how effectively this was done. The FCP has been criticized for measuring functioning in relation to pre-morbid levels (Ramsberger, 1994) and to be linguistically biased, with no measure of non-verbal communication (Cunningham et al., 1995). A number of observational profiles have been published since, including the Revised Edinburgh Functional Communication Profile (Wirz et al. 1990) and the well-known American-Speech-Language-Hearing Association Function Assessment for Communicative Skills in Adults (ASHA FACS; Frattali, Thompson, Holland, Wohl \& Ferketic 1995). The publication of the ASHA-FACS in 1995 is a good example of the influence of the International Classification of Impairment, Disability and Handicap (ICIDH), which later became the International Classification of Functioning (ICF) Organization, 1980, 2001). Based on the ICIDH framework, researchers and clinicians expanded the concept of functional communication beyond the ability to transmit a message or to communicate, to an outcome measure that reflects the functional consequences of the impairment, as measured by problems experienced in daily life activities. As will be discussed below, the concept was later expanded to measures of the impact of impaired communication on well-being and quality of life (Elman \& Bernstein-Ellis 1995). The ICF is widely used in speech and language therapy as a framework to describe functioning at different levels. Traditional aphasia assessment is defined at the level of impairment. This is separated from how that impairment in language affects a person's ability to undertake activities such as speaking on the phone. This in turn is separated from their level of participation in everyday life, and the ICF also defines personal and external factors that might be of influence across these different levels of functioning. Barnes \& Bloch (2018) argue that the ICF is not able to capture everyday communication as it gives a limited view of communication as a fundamentally individual competence, that can be standardized separately from different contextual variations. Glueckauf et al. (2003) criticised the ASHA-FACS for measuring the degree of independence in communication (i.e. can someone perform a task without help), but not including a measure of communicative success (i.e. how effective is communication). Functional communication is quantified in these observational profiles as an overall score of ability, effectiveness or independence on a number of behaviours or communicative activities, such as 'expresses feelings', 'tells time', or 'participates in conversations'. They considered by some to be subjective and indirect measures of functional communication (Blomert et al., 1987, Glueckauf et al., 2003, van der Meulen et al. 2010). 


\subsection{Observational profiles (client or proxy rated)}

The third category includes observational profiles that are rated by the client or a proxy (e.g. a partner or carer) rather than a clinician. These instruments are built on the assumption that the clinician only has a limited opportunity to observe the client in everyday situations (Lomas et al.

1989), while the proxy has a much better sense of the level of functioning of the client in day-to-day life. In addition, Davidson \& Worrall (2000, pg 31) suggested that clinicians may focus more on the potential of the client rather than actual performance in their judgements of functional communication. On a larger scale, health care has shifted its focus to becoming more person-centred, meaning the value attributed to the client's perspective in therapy goal setting (Worrall, 2006) and their judgement of what represents meaningful therapy outcomes has become increasingly important for health care providers (Wallace et al. 2016). The inclusion of the client perspective in therapy outcome measures has thus become a key part of health care policy making (Frattali et al. 1995 Holland \& Thompson, 1998, Rudd, 2016, Irwin, 2012).

Observational profiles that aim to measure functional communication in aphasia include the Communicative Effectiveness Index (CETI; Lomas, Pickard, Bester, Elbard, Finlayson \& Zoghaib, 1989), the Assessment of Communicative Effectiveness in Severe Aphasia (ACESA; Cunningham, Farrow, Davies \& Lincoln, 1995), the Functional Outcome Questionnaire for Aphasia (FOQ-A; Glueckauf, Blonder, Ecklund-Johnson, Maher, Crosson \& Gonzalez-Rothi, 2003), the Communicative Activity Log (CAL; Pulvermuller \& Berthier, 2008), the Communication Outcome after Stroke, client and farer version (COAST and carer COAST; Long, Hesketh \& Bowen, 2009, Long, Hesketh, Paszek, Booth \& Bowen, 2008) and the Aphasia Communication Outcome Measure (ACOM; Doyle, Hula, Hula, Ross, Wambaugh, Schumacher \& Roehrig, 2012). Measures such as the COAST have expanded their definition of functional communication outcome to include measures of the impact of the communication impairment on the client's life. The criticism for observational profiles as discussed in the previous section also applies here: they are considered to be subjective and indirect measures of functional communication (Blomert et al., 1987; van der Meulen et al., 2010). In addition, it has been suggested that the observations by a proxy can be biased by factors relating to their relationship with the PWA and by their own emotional well-being (Glueckauf et al., 2003). Functional communication is quantified in a similar fashion as for the clinician rated observational profiles: as an overall score of ability, effectiveness or independence on a number of communicative behaviours. 


\subsection{Linguistic analysis of connected speech}

Finally, there is a group of instruments that is based on the linguistic analysis of connected speech. As interest grew in what PWA could communicate at a conversational level, knowledge

from studies on pragmatics and discourse has been applied to the analysis of conversation in aphasia.

Both fields study language above the sentence level and are thus, in theory, relevant to the discussion of functional communication in aphasia. Examples of instruments are the Correct Information Unit Analysis (CIU; Nicholas \& Brookshire, 1993) and the Information Units approach (IU; McNeil, Doyle, Fossett, Park \& Goda, 2001) which aim to assess the informativeness of connected speech by identifying phrases (or units) that represent crucial, relevant information for a specific story. The informativeness of a story that is retold is defined by the number or percentage of units that are expressed correctly and intelligibly. It is, however, difficult to achieve high inter-rater reliability on these measures (Oelschlaeger \& Thorne, 1999: Ramsberger \& Rende, 2002). Both measures also focus solely on spoken language. Another instrument that is based on linguistic analysis of functional communication is the Pragmatic Protocol (PPL; Prutting \& Kirchner, 1987). The PPL is an observational tool, but is discussed in this category because of its linguistic origins. The tool can be used to indicate whether a set of pragmatic aspects of language are observed or not in conversation, such as "turn taking interruption/overlap", "physical proximity" and "vocal intensity" (Prutting \& Kirchner, 1987). The pragmatic aspects of behaviour, if observed, are also judged on whether they are applied appropriately (i.e. to facilitate or neutrally influence communication) or inappropriately. The aim of the PPL is thus to identify a pattern of pragmatic behaviour impairments, based on the observation of 15 minutes of spontaneous conversation. The PPL is an observational tool and therefore, the same criticism applies as for the second and third categories mentioned above. Finally, Conversation Analysis (CA) surfaced around the turn of the 20th century, which emphasized the study of natural, spontaneous conversation in aphasia (Beeke et al., 2007, Damico et al., 1999). This method underlines the importance of studying spontaneous everyday conversation (Beeke et al., 2007) and to take into account the interactive and multimodal nature of conversation, such as the use of eye gaze and gesture. CA is based on the assumption that conversations are products of a structured interaction in which the sequential order of turns represents an important organizational feature of conversation. The overall aim of CA in aphasia is to analyze what causes conversational problems and disruptions of the organization, and to identify adaptive strategies to overcome these problems. This methodology has provided useful information 
for the assessment of natural conversation and therapy planning (Beeke et al., 2007; Wilkinson, 2015). Due to the observational nature of the methodology, it remains difficult to synthesize findings from $\mathrm{CA}$ and to describe behaviour at the group level, though a number of attempts have been made (Perkins et al. 1999, For a brief discussion, see Prins \& Bastiaanse, 2004).

\subsection{Interim summary}

A wide range of instruments have been created to measure functional commmunication, each with different purposes: either to determine treatment effectiveness, generalization of therapeutic interventions, to use for therapy planning or to develop our theoretical knowledge on functional communication in aphasia. The conceptualizations and operationalizations of functional communication in the literature show overlap, as all aim to capture language or communication in conversation or even everyday life. In a theoretical sense, however, they are quite different (Irwin et al., 2002 Linnik et al., 2016). Some measures assess interactive aspects of communication (ASHA-FACS), while others only assess the transactional aspects (CADL-2, ANELT). A number of measures define functional communication as multimodal (Conversation Analysis, Scenario Test), while others focus solely on linguistic exchanges (ANELT; CIU). Some instruments aim to capture difficulties in communication (CADL-2), while others include measures of the experience or impact of living with a language impairment (COAST; ACOM). The variety across these instruments reflects the challenging nature of capturing a complex, multi-variable phenomenon such as everyday communication. A clear definition is imperative, however, in order to interpret and synthesize findings and draw overall conclusions about communication in aphasia (Wallace et al., 2017; Brady et al. 2016). Brady et al. (2016) referenced up to 11 different instruments that aim to capture functional communication in the most recent Cochrane review on aphasia rehabilitation. Though functional communication was identified as the primary outcome measure for SLT, the authors used secondary measures to quantify therapy success, "given the lack of a comprehensive, reliable, valid and globally accepted functional communication tool" (Brady et al. 2016). Most recently, the core outcome set (COS) initiative for aphasia treatment research reported on reaching consensus on the essential instruments for measuring language impairment, emotional well-being and quality of life. No con-

sensus was reached for communication, however, possibly due to the the lack of understanding of the concept of effective communication and the complexity (multi-factorial nature) of the construct (Wallace et al. submitted). In order to better understand functional communication, it is imper- 
ative that a comprehensive model of communication is proposed that, based on existing research, clearly defines what variables it does and does not include.

\section{A definition of situated language use}

Clearly, language use in everyday life is a complex, multi-faceted, dynamic phenomenon that the field of aphasiology is struggling to define and measure in a uniform way. Over the past decades, however, much research has been done on this topic with healthy adults in the fields of communication science, psychology, neuroscience, psycholinguistics and sociology. This research provides important clues on what components influence a person's ability to use language in a real world setting, in addition to a person's linguistic skills. This knowledge can, in turn, inform the endeavours in aphasiology to develop a theoretically founded definition everyday communciation (Simmons-Mackie et al., 2014, Brady et al., 2016; Webster et al., 2015, Whitworth et al., 2015). In this section we will propose a model of language as it is used in everyday life that captures a number of universal principles that govern communication and that will help us get a better grasp on this complex concept. The three core principles are taken from Clark (1996). Situated language use, or communication, is (1) interactive, (2) multimodal and (3) reliant on common ground (Clark, 1996). Using those three principles, we will also sketch the internal factors (i.e. cognitive skills) and the external (environmental) factors that are likely to be important for situated language use. This is necessary in order to define what measures should be taken, and the focus for further empirical work. A brief review of the literature for each principle will be described. In each section, what we know from research with healthy adults as well as with PWA will be summarised. Finally, the best setting in which to study and measure situated language use will identified.

\subsection{Language use is interactive}

Many researchers agree that language use or communication is a joint activity (Clark, 1996, Schegloff, 1982). This means that language is achieved by two or more people who coordinate their actions to achieve a common goal. Every decision made during a conversation will depend on the actions of the other. The two individual contributions to a conversation are referred to as participatory actions (Clark, 1996). Language use is therefore an inherently interactive process, in which two or more participants work together and coordinate their actions to create meaning. The 
whole, as well as the participatory actions of each individual can be studied within that process. This means that when language production and comprehension are studied outside of the interactive process (i.e. in isolation, or based on the behaviour of one person), they will be tapping into inherently different processes as compared to language when it is used for communication. The language processes will, in both situations, also have different task demands. The interactive nature of communication is therefore a core feature of communication and situated language use that should be taken into account when assessing language performance in a real world setting Clark, 1996: Schegloff, 1982). Research with healthy adults shows that having the chance to interact with a conversation partner greatly improves communicative efficiency (Clark \& Krych, 2004), compared to language performance of a single individual on a similar task, due to the availability of feedback and the co-ordination of actions between two interlocutors. Indeed, previous studies have shown that interlocutors help each other in creating meaning and dialogue by providing each other with feedback (Brunner, 1979: Schegloff, 1982, Clark \& Brennan, 1991, Clark \& Krych, 2004). Addressees can provide immediate feedback on the message by providing so-called 'back channels', 'minimal turns' or 'continuers', i.e. signals such as "uh huh", "right", "okay", nods, smiles or frowns (through any modality, as discussed in the next section), to indicate attentiveness and involvement of the addressee, comprehensibility of the message and the addressee's personal response to the content (Brunner, 1979, Schegloff, 1982, Clark \& Brennan, 1991; Clark \& Krych, 2004). Speakers have been shown to monitor their addressees for backchannels and adjust their messages depending on the type of feedback they observe, for example the need for repair or elaboration of the message (Clark \& Krych, 2004 Tolins \& Fox Tree, 2014). Backchannels have been shown to influence the content of speaker dialogues: research has shown that different types of backchannels can lead to significantly different ways in which a story is told, while the absence of certain backchannels resulted in less climactic endings, qualitatively worse story content and modulated use of abstract language use (Bavelas et al. 2000: Beukeboom, 2009, Norrick, 2010; Tolins \& Fox Tree, 2014). Kendrick \& Drew (2016) nicely describe the many different ways in which the need for assistance can be made clear during interaction. At one end of the continuum are self-initiated, explicitly stated requests for feedback, such as when someone stops mid-sentence and asks their conversation partner for help, i.e. "what's the word?". Further along the continuum are the trouble alerts, which signal a difficulty, but not what the difficulty is, nor is it an explicit request for help, such as the exclamation "oh", "damn it" or "oops". At the other end of the continuum, the addressee initiates help based on 
an anticipated opportunity for assistance, without having been asked and before the trouble even arises. An example of this is the provision of communicative supportive materials when starting to discuss a specific topic. A continuum such as this emphasizes the wide range of explicit to more subtle signals that are used during interaction to signal understanding or misunderstanding, as well as the need for help. For a review on how healthy adults and PWA can use the communicative context (what has been said/communicated) to construct their utterances, please refer to section 3.3

In the aphasia literature, many researchers have emphasized shared responsibility of constructing conversation between interlocutors (Milroy \& Perkins, 1992, Simmons-Mackie et al., 2014, Goodwin 1981, 1995). A large body of research has focused on conversational repair, i.e. how problems or breakdowns in conversation are dealt with by the PWA and their conversation partner (Lindsay \& Wilkinson, 1999, Milroy \& Perkins, 1992, Schegloff, 1982). Often, this is done by analyzing turn-taking patterns during conversation which, according to Conversation Analysis (CA) principles, can reveal how people understand and respond to each other during interaction (Beeke et al. 2007; Sacks et al., 1974, Schegloff, 1982). Through this approach, it been shown that the PWA can rely on the conversation partner in the co-construction of dialogue and meaning in communication when the PWA experiences problems in conversation (Beeke et al., 2007, Lindsay \& Wilkinson, 1999, Oelschlaeger \& Damico, 1998, Booth \& Perkins, 1999). Research has shown that conversation partners can be actively involved in constructing PWA's contributions to conversation, i.e. in helping the PWA express themselves. For example, conversation partners have been shown to help the PWA in completing conversational turns when word finding difficulties occur (Bloch \& Beeke, 2008 Oelschlaeger \& Damico, 1998), and in repairing turns when the PWA experiences a communication breakdown more generally (Lindsay \& Wilkinson, 1999 ; Perkins, 1995; Samuelsson \& Hyde, 2016). Non-aphasic conversation partners have thus taken on some of the PWA's conversational burden in order to avoid communication breakdowns. Indeed, the degree of communicative burden, as experienced by the conversation partner, has been related to the severity of the communication difficulties of the PWA. The more communication difficulties, the higher the experienced communicative burden by the conversation partner (Linebaugh, Kryzer, Oden \& Myers, 2006). Crucially, the degree of communicative burden the conversation partner takes on during conversation can be too little (increasing the chance of breakdowns for the PWA) or too much 'speaking for' the PWA without sufficient information to do so successfully), in both cases negatively affecting conversational flow 
(Linebaugh et al. 2006).

The facilitative effect of the conversation partner, however, seems to depend on who the PWA is speaking to. Conversation partners have been shown to respond differently to breakdowns in conversation, while PWA show different patterns of conversational repair depending on who they're speaking with. Eriksson et al. (2016) have, for example, provided initial support for the idea that individual characteristics of the conversation partner, such as their executive function skills, influence their abilitiy to provide communicative support for the PWA. Executive function skills can, for example, influence the ability to hold several possible interpretations of the expressed message in mind, or to guide conversation to a particular end goal. The influence of different conversation partners has also been shown for SLTs compared to PWA's spouses (Laakso, 2014b Lindsay \& Wilkinson, 1999, Perkins, 1995). The difference between these two groups of conversation partners has often been explained by the 'institutional' nature of conversation with the SLT, while conversation with a spouse is more 'peer'-like in nature. In addition, differences in the amount of shared knowledge and individual discourse styles have also been proposed as possible explanatory factors (Green, 1982, Perkins, 1995: Wirz et al. 1990; Laakso \& Godt, 2016, Howe et al., 2008). Ferguson (1994, 1998) attempted to systematically assess the effect of familiarity as well as the degree of knowledge of aphasia across conversation partners on communication. In both studies, no effect of familiarity or knowledge of the language impairment on conversational repair was found. These findings are not well generalizable, however, as those selected as non-familiar conversation partners knew the PWA quite well and did not differ enough from the familiar conversation partners (Ferguson, 1994). Ferguson (1998), in turn, did not take into account non-verbal communication when assessing communication efficiency. Unfortunately, it remains largely unknown how familiarity of the conversation partner affects communicative efficiency of the PWA. The belief that it does have an effect on communication is underlined by, for example, the fact that the disability questionnaire of the Comprehensive Aphasia Test (CAT, Howard et al. 2004) includes questions regarding the ease of speaking to and understanding a familiar conversation partner compared to a stranger.

A larger body of research has shown that expanding the conversation partner's knowledge of aphasia and training them to use communication strategies can improve overall communication „with PWA (Kagan et al., 2001, Lindsay \& Wilkinson, 1999, Nykanen et al., 2013, Simmons-Mackie et al., 2010, Wilkinson \& Wielaert, 2012, Pound et al., 2000, Lesser \& Algar, 1995, Rayner \& Marshall, 2003, Howe et al. 2008, Cruice et al., 2018). Most of these studies are based on the idea 
that communication strategies employed by the non-aphasic conversation partner can create an environment that enables the PWA to communicate optimally, i.e. that changes in the conversation partner's behaviour can reveal the PWA's communicative competence (Kagan et al., 2001; Turner \& Whitworth, 2006). For example, volunteers who were trained to use communication strategies and taught about what aphasia is, improved on measures that assessed their ability to acknowledge and reveal the competence of PWA. In addition, changes were also noted in the PWA's degree of participation in conversation (Kagan et al., 2001, Wilkinson et al., 2010). Based on these findings, a number of therapies have been developed with the intention of improving the conversation partner's skills to maximally facilitate conversation with the PWA and to reveal the PWA's communicative competence (Simmons-Mackie et al., 2010, Kagan et al., 2001). A slightly different approach has emphasized the collaborative aspect of conversation and the importance of training both the conversation partner and the PWA to use communicative strategies (Beckley et al., 2017 Simmons-Mackie et al., 2010, Wilkinson et al., 2010, Lock et al., 2001; Wilkinson \& Wielaert, 2012 Nykanen et al. 2013). These studies have provided support for the idea that therapy can be used to directly influence communication between the PWA and their conversation partners.

Very little research has been completed on the benefits for the PWA of being able to give and receive feedback during interaction. If healthy adults have been shown to adapt their output during conversation in response to feedback from their conversation partners, how does feedback influence a PWA's communication? Can PWA use this feedback to their advantage and change their output to improve comprehension of their conversation partners? Do PWA provide their conversation partners with clear feedback on their own level of understanding? A few studies have looked at the types of explicit feedback provided by SLTs during intervention, such as direct or delayed comments on the effective use of communicative strategies such as drawing or writing (Horton, 2008 Simmons-Mackie et al., 1999 , Beckley et al., 2017). This is often unnatural, therapeutic feedback, which is not relevant for the discussion of spontaneous communciation in everyday life. In a large study on communication skills in conversation in patients with left and right hemisphere strokes, Rousseaux et al. (2010, p. 1105) report a relative preservation of the ability of people with a left hemisphere stroke to attend to their interlocutor for engagement in the conversation and to manage nonverbal feedback from their conversation partner. Producing feedback was also found to be preserved, which suggests that these subjects "were still able to use it to partially encompass their difficulties in understanding the interlocutor" (Rousseaux et al., 2010, p. 1105). 
Perkins (1995) reported on three PWA who used 'minimal turns' such as 'mm hm' effectively to contribute to the conversation without taking on elaborate turns that require the use of more complex linguistic resources. Furthermore, Walker et al. (2016) reported on the production of back channels by PWA to display different levels of understanding in conversations with their SLT, such as the production of 'oh' at the beginning of an utterance. Subtle differences were found between back channels produced by the PWA that indicated claims of understanding, or the more definite displays of understanding. SLTs were shown to be sensitive to these differences and respond with elaborations to claims, while affirmations or changes of topic followed the more definite displays of understanding (Walker et al. 2016). The feedback provided by the PWA thus influenced the course of conversation and helped to ensure mutual understanding. Finally, the use of feedback such as back channels has been trained during conversation therapy in dyads. Beeke et al. (2011) report on a therapy in which the PWA was explicitly and successfully trained to signal verbally (e.g. "um" or "erm") and non-verbally (e.g. grimacing, raising eyebrows) that he was still actively working on his turn. Normally, this subject would frequently leave long pauses during which it was unclear whether he intended to continue his turn or not. Findings such as these underline the important role of feedback and that the use and understanding of feedback during communication can be affected (directly or indirectly) by the presence of aphasia. It seems to be the case that some PWA can use some forms of feedback during conversation to inform their conversation partner of their level of understanding and involvement in conversation, and that the provision of this kind of feedback can, to some degree, be trained through therapy. Whether there is a difference in the type of feedback (more automatic or natural behaviours such as grimacing and "um" verbalizations compared to "sorry?" "I don't understand") is still unclear. If and how PWA can use different kinds of feedback from their conversation partner to improve their own communication, remains unknown.

The use of feedback from a conversation partner is a form of monitoring the conversation, i.e. in addition to keeping track of what is said, also having the flexibility to reflect on the correctness of what has been said and whether or not your conversation partner can still follow. Another form of monitoring happens through monitoring one's own speech output and understanding, without external prompting (Postma, 2000), this is also referred to as self-monitoring. Self-monitoring occurs frequently in subjects without brain impairment. Research suggests that generally speaking, self-monitoring is difficult for PWA (Oomen et al., 2001, Schlenck et al., 1987), though there are 
differences across aphasia types. Most studies have reported on a lack of self-monitoring and lack of error awareness in participants with jargon aphasia (Marshall, 2006, Sampson \& Faroqi-Shah, 2011; Marshall et al., 1998). Less research has been done on self-monitoring in participants with non-fluent aphasia (Oomen et al., 2001). For both types of aphasia, the underlying process and impairment in self-monitoring remains unclear, though different hypotheses have been discussed relating to selfmonitoring in the comprehension and/or production processes (Hartsuiker \& Kolk, 2001, Postma 2000 Nozari et al., 2011; Huettig \& Hartsuiker, 2010; Levelt, 1989). Often, picture-naming or picture-description tasks are used to elicit errors and to observe self-monitoring behaviour. To the knowledge of the authors, no research has been done on self-monitoring during communication, or how this is influenced by the presence of a conversation partner, for example.

\subsection{Language use is multimodal}

Communication is a fundamentally multimodal phenomenon (Bavelas \& Chovil, 2000, Clark. 1996: Kendon, 1980, McNeill, 1992, Vigliocco et al., 2014). A number of different modalities or channels of expression are used during communication, such as facial expressions, gesture, prosody, speech and body movements. These channels interact and are interdependent: they integrate into a single composite message. Channels are combined to replace, supplement, complement and emphasize speech, as well as to express emotion (Bavelas \& Chovil, 2000, Kendon, 1980, 2004, McNeill 1992). Language as a linguistic entity represents just one of the channels that can be used for communication. The study of language, within and outside of aphasiology, has largely focused on language as a decontextualised linguistic phenomenon. By studying language in isolation, the complexity and interdependence of the different channels is ignored (Vigliocco et al. 2014), and a wealth of information that is relevant for communication is missed. When people communicate with each other in the real world, they use all channels to express meaning, as well as to monitor and understand what the other participant is communicating (Clark \& Krych, 2004). Communicative success or ability cannot be determined by the evaluation of a single channel, such as the language channel, as the PWA might have communicated or understood essential information through gesture, prosody or any other communicative modality.

In the clinical and academic setting it is generally accepted that PWA can use other modalities such as gesture, facial expressions, body posture and movement and prosody in addition to the 
impaired verbal modality to achieve successful communication (Rose, 2006). Crucially, a large number of measures of functional communication do not systematically take into account all the modalites. Very few studies have actually evaluated the interplay of all modalities that are said to be involved in communication. Instead, different fields of research have developed, each focusing on a specific channel such as gesture. A brief overview of the relevant research on each modality in healthy controls and PWA will be discussed here.

\subsubsection{Gesture}

The field of gesture in non-brain damaged controls is abundant, and a thorough review of the literature is beyond the scope of this article (for a review, see Hostetter, 2011; Kendon, 1994). Of interest for the current discussion is the role of gesture in multimodal communication, i.e. how much information is transmitted through the gesture modality in communication. Generally speaking, research has shown that gesture, in the presence of speech, has a communicative function(Hostetter, 2011: Kendon, 2004). Indeed, in some contexts, the manual modality has been shown to carry 50$70 \%$ of the information of the overall message (Chovil, 1991-1992). Comprehension of a message is facilitated and improved when gesture and speech are presented together (Holler et al., 2017, Holler \& Wilkin, 2009, Kelly et al. 2015, 2010). This has even been shown in a more naturalistic face-to-face communicative setting (Holler et al., 2009). According to the integrated systems hypothesis, the integration of information from both modalities happens automatically (Kelly et al. 2015, 2010). How much interlocutors rely on gesture to produce or comprehend a message, however, depends on a number of factors such as the type and complexity of information that is communicated (concrete or abstract, i.e. how easy or difficult it is to convey information in gesture) and whether the information is already present in speech or not (Hostetter, 2011). In addition, the assumption is often made that language proficiency, i.e. the degree to which a person can express or comprehend the entire message by relying solely on the verbal channel, also influences how much gesture is relied on in communication. When language skills are non-optimal, such as in non-native speakers, in children and in populations with language problems due to neurological or developmental impairments, it is often assumed that gesture can (partly) compensate for the loss in verbal abilities. A number of studies suggest that children's comprehension and learning of complex concepts is better when gestures are combined with speech compared to presenting them with just verbal information (Singer \& Goldin-Meadow, 2005, Ping \& Goldin-Meadow, 2008: Wakefield 
et al. 2018). Veinott et al. (1999) conducted a study to measure the influence of gesture alongside speech in non-native speakers compared to native speakers. The non-native speakers who could not use their language channel optimally due to a lack of proficiency, benefitted from the use of other communicative channels in communication such as gesture to supplement their comprehension.

There is a growing body of research on gesture in aphasia (for a review, see Rose, 2006, Rose et al., 2013). Most of the research on gesture has focused on non-fluent aphasia, with a smaller number of studies that have evaluated gesture in fluent aphasia (for example, see Carlomagno et al. 2013). Overall, research has shown that PWA produce gesture in communication. Some research suggests that PWA produce more gestures compared to non-brain damaged controls (Carlomagno et al. 2005, Rousseaux et al. 2010, Sekine \& Rose, 2013) but that they differ in the types of gestures they produce in spontaneous speech (Sekine \& Rose, 2013, van Nispen et al., 2016). PWA with a relatively intact conceptual system, as typically seen in non-fluent aphasia, were found to produce more meaningful gestures (Sekine \& Rose, 2013), whereas those with a more fluent aphasia used more abstract and unspecified gestures (Cicone et al. 1979, Sekine \& Rose, 2013). PWA with less severe linguistic impairments, such as in anomic aphasia, produced the types of gestures that were comparable to controls. Keeping in mind that the number of studies is small, a number of researchers have, based on findings such as these, proposed that gesture and language rely on the same underlying system and break down together in aphasia (for a brief discussion, see Hogrefe et al. 2012, Cicone et al., 1979).

In addition to looking at gesture production as such, researchers have also looked at the communicative effectiveness of gesture in aphasia. These studies show that gestures can add communicative „value to the message conveyed by PWA in speech de Beer et al., 2017, Hermann et al., 1989, Hogrefe et al., 2013, Mol et al. 2013, Rose et al. 2017). One study showed that on average, between $22 \%$ - $92 \%$ of gestures produced by PWA were essential for understanding their message, as compared to $5 \%$ for controls (van Nispen et al., 2017). These essential gestures conveyed information in the absence of speech, added information that was missing in speech or helped clarify information presented in speech (Dipper et al., 2015, van Nispen et al., 2017). These findings would argue against the simultaneous breakdown of gesture and language, as gesture compensates for loss of meaning in the linguistic channel. Therapy studies have shown that the use and/or comprehension of gesture can improve after gesture-training (Daumüller \& Goldenberg, 2010, Marshall et al., 2012, 
2013, Roper et al. 2016), even with effects shown on communication measures (Caute et al., 2013). Many of the studies on gesture production employ decontextualized gesture elicitation methods that lack the interactive, co-constructive nature of face-to-face communication. It has been emphasized that different communicative situations may elicit different gesture behaviours (Hogrefe et al. 2012). It therefore remains unclear whether the abovementioned results can be generalised to face-to-face communication. Rose et al. (2017) suggested that the lack of ecological validity in these studies might underestimate the communicative effectiveness of gesture in aphasic speech. Their study of spontaneously produced pantomime gestures in conversational discourse showed that speech and gesture combined had a strong communicative effect in aphasia (Rose et al., 2017). In a semi-structured conversational setting, even PWA with severe aphasia were shown to compensate for their verbal impairment by producing meaning-laden gestures (Hermann et al., 1989; Rose \& Douglas, 2003). The same was found in a smaller study of spontaneous conversation between subjects with severe aphasia and a friend (Hermann et al. 1988). Importantly, a number of studies have suggested gesture production can be influenced by two factors that frequently co-occur with aphasia: the presence of limb apraxia and impaired semantic processing (Cocks et al., 2013, Fucetola et al., 2006; Hogrefe et al., 2012, van Nispen et al., 2016). Overall, it seems gesture plays an important role in communication in aphasia. How gesture contributes to the comprehensibility of the PWA in face-to-face communication, and how gesture interacts with the language component in conversation remains largely unknown (de Beer et al., 2017, Rose, 2006).

Much less research has been done on gesture comprehension in aphasia. A number of studies have suggested that gesture comprehension is impaired in aphasia (Gianotti \& Lemmo, 1976 Rousseaux et al. 2010), and that comprehension difficulties are more frequent in PWA with seman540 tic processing difficulties and PWA with posterior lesions compared to anterior lesions Cocks et al. 2009: Daniloff et al., 1986, Ferro et al., 1980, Gianotti \& Lemmo, 1976). Non-fluent aphasia, in turn, has been related to normal gesture comprehension (Rose, 2006). A few small studies have assessed the added value of observing multiple channels (gesture and speech, for example) in comprehension. Results have shown that adding gesture to speech can lead to improvements in comprehension in aphasia (Cocks et al. 2009, Eggenberger et al., 2016, Yorkston et al., 1979). Interestingly, it is still unclear whether PWA benefit from the presentation of multiple modalities by integrating the available information (multimodal gain; Eggenberger et al., 2016; Yorkston et al., 1979), or by relying on a single, possibly less impaired, modality such as gesture (Cocks et al., 2018, 2009). Records 
(1994), for example, showed that as ambiguity increased in speech, PWA relied more heavily on gesture (pointing behaviour) to construe meaning. Cocks et al. $(2018,2009$ ) hypothesized that the lack of multimodal gain observed in their study could be caused by an impaired allocation or reduced availability of attentional resources, which prevents PWA from processing all the available information. When gesture and speech provide congruent information, however, it seems possible for gesture to contribute to improved comprehension in communication in aphasia, either by contributing to a multimodal message or by offering an alternative channel to rely on in communication. As in production, gesture comprehension is also said to be affected by the presence of limb apraxia (Eggenberger et al., 2016). The methodological limitations of the studies that have been done currently make it difficult to generalize findings to situated language use. It therefore remains unknown how gestures produced by the conversation partner during communication contribute to comprehension of the PWA, as well as to the overall efficiency of communciation.

\subsubsection{Face and eye movements}

In non-brain damaged controls, it has been shown that people monitor each other's faces closely during conversation. Interlocutors gather information from facial movements (Bavelas \& Chovil, 2000, Ekman, 1979, 1997, Clark, 1996), eye gaze (Hanna \& Brennan, 2007, Goodwin, 1981, Kendon,

1967), lip movements (McGurk \& MacDonald, 1976) and eyebrow movements (Flecha-García, 2010) to inform communication. Much research has been done on facial expressions and how they convey an underlying emotional state of a person (Parkinson, 2005). In interaction, facial expressions or facial movements can serve a communicative function on their own, or in combination with other signals such as speech (Chovil, 1997, Frith, 2009). In the communicative approach to facial movements, it is assumed that facial expression can be used to communicate efficiently on a wide variety of topics, including emotions (Chovil, 1997). Facial expressions can be used for linguistic purposes such as marking emphasis (Birdwhistell, 1970), indicating understanding, dislike, confusion and disbelief or difficulty in recalling an event (Chovil, 1991-1992, Ekman, 1979). Facial expressions have also been shown to indicate levels of speaker certainty (Swerts \& Krahmer, 2005; Dijkstra et al. 2013). Eyebrow movements have been related to structuring and emphasising information in a verbal message (Flecha-García, 2010, Ekman, 1979). Smiles, along with nods and verbal expressions such as 'yeah', have been shown to function as backchannels to indicate continued attention and involvement in conversation, to signal the listener's level of understanding and to signal the 
listener's level of agreement (Brunner, 1979). Many of these facial movements are argued to only interpretable in their conversational context, and not stand on their own necessarily (Chovi 1997). Furthermore, research has shown that gaze plays an important role in coordinating face-toface communication (Kendon, 1967, Bavelas et al., 2002, Hanna \& Brennan, 2007), for example by regulating turn exchanges (Kendon, 1967; Bavelas et al., 2002; Goodwin, 1981). Gaze can also be relied upon as an indication of continued attention and the direction of attention (Argyle \& Cook 1976, Goodwin, 1981, Itier \& Batty, 2009, Emery, 2000). Speakers use gaze to monitor addressees' understanding (Kendon, 1967), to seek and elicit a response and feedback (Bavelas et al., 2002 Rossano, 2013), to resolve temporal ambiguity in conversation (Hanna \& Brennan, 2007), to emphasize or reinforce a verbal message and to monitor conversation for possible difficulties (Emery 2000). Gaze has been shown to combine with other cues (for example with speech and other signals from the face) in complex ways to create a composite message (Argyle \& Cook, 1976). Visual cues from lip movements have been shown to help listeners anticipate what auditory information is coming, such as in the case of auditory and visual incongruencies (McGurk \& MacDonald, 1976), or when there is noise on the auditory signal (e.g. Jordan \& Sergeant, 2000).

A different line of research has assessed the effect of visibility of the conversation partner's face on the efficiency of communication. Rather than focusing on specific elements of the face, these projects assess the effect of being able to see the face of the other speaker compared to not being able to see the face at all, and thus assessing the combined effect of the above mentioned elements. A number of studies have shown that efficiency on a collaborative task is heightened when the interlocutors can use the visual channel in communication (Boyle et al., 1994). Efficiency, in this case, was measured by the total time and the number of turns it took to complete the task. Overall performance was not affected in this study, meaning that subjects could still complete the task successfully without the use of the visual channel, but it took them longer and it required more turn exchanges between the interlocutors. This effect depends on the type of task, however. Whereas Boyle et al. (1994) used a map-navigation task, Lysander \& Horton (2012) and Clark \& Krych (2004) found no facilitative effect of mutual visibility on their collaborative card-matching and lego-building tasks, respectively. Instead, efficiency depended on having a shared view of the task-relevant materials, of the objects both interlocutors were referring to (i.e. when it affected common ground, see section 3.3. Lysander \& Horton (2012) argued that the lack of effect of mutual visibility on task efficiency was likely to have been caused by the need to attend to the 

independent of co-speech gesture, PWA showed a reduced fixation on the speaker's face. This could indicate that PWA did not, or could not, compensate for their difficulty in comprehension of verbal information by focusing on visual cues from the face. In their case-study, Youse et al. (2004); Schmid \& Ziegler (2006) showed PWA did not benefit from the bi-modal presentation (visual and

cards and their critical differences between the pictures. In addition, it seemed the healthy controls in their study were able to solve communicative difficulties through other modalities, such as the verbal one. These healthy adults might not have needed the additional information from another modality to understand their interlocutor. In short, during communication, a lot of information can be conveyed through the face, independently or combined with other modalities such as gesture and language.

In aphasia, much less research has been done on the influence of face and eye movements in conversation. In production, PWA have been shown to use facial movements in interaction to show emotions (Laakso, 2014a) and to indicate problems in conversation, such as with eyebrow movement, smiling and laughter (Laakso, 2014a; Kaukomaa et al. 2014). Goodwin (1995) provided a detailed description of how a man with severe aphasia used eye gaze to inform his conversation partner in of his attentiveness to what is being said, as well as to demonstrate his departure from being a listener by diverting his gaze. Overall, PWA with left hemisphere lesions are often assumed to have intact pragmatic abilities in communication, which would include face and eye-movements as described above.

Very little research has looked at the use of visual information from the face by PWA to aid communication. A few studies have suggested that PWA might have difficulty integrating auditory and visual information (Preisig et al., 2015, Youse et al., 2004: Schmid \& Ziegler, 2006). This is line with the claim that PWA might not be able to benefit from multimodal gain in their comprehension of gesture (Eggenberger et al., 2016). Preisig et al. (2015) suggested that the impairment of the auditory channel interferes with the integration of that signal with the available visual information. According to Preisig et al. (2015), PWA then rely on the signal that carries the most information (the auditory signal), rather than on the combination of the two. For example, Preisig et al. (2015) showed that during co-speech gesture, PWA exhibited similar fixation patterns compared to healthy controls on the speaker's hands when they were observing natural dyadic conversation. Interestingly, auditory), compared to the unimodal condition (auditory), on a speech perception task. This 
supports the claim that PWA have difficulty integrating information from different modalities. From the literature it remains unclear whether or not PWA rely on visual information from their conversation partner's face to better comprehend their message.

\subsubsection{Prosody}

In addition to the content of the verbal message (what we say), we can convey information by changing the way in which we say something. Prosody refers to variations in speaking rate, pitch, loudness and voice quality that each play a part in conveying meaning (Hellbernd \& Sammler, 2016). In healthy controls, a large body of research has provided support for the idea that the manner in which we say something can change the meaning of a message at a linguistic and a paralinguistic level (Bolinger, 1986, for reviews, see Hellbernd \& Sammler, 2016, Wagner \& Watson, 2010 Cole, 2015, Cutler et al., 1997). At a linguistic level, prosody can express semantic relationships, disambiguate syntactic structures (Cutler et al., 1997; Wagner \& Watson, 2010), group words into phrases (Wagner \& Watson, 2010), signal the relative prominence or importance of a word and by signalling illocutionary force (marking an utterance as a statement, question, etc.) (Wagner \& Watson, 2010, Cole, 2015, Witteman et al., 2011, Eberhard et al., 1995). Paralinguistically, prosody conveys information regarding the emotional state of the speaker (Cole, 2015, Scherer, 1986), as well as speaker certainty, confidence and doubt (Swerts \& Krahmer, 2005, Jiang \& Pell, 2017) and speaker attitude and beliefs (Bolinger, 1986, Ladd, 1996). Prosody has also been found to play a role in the managing of interaction, also referred to as conversational prosody, for example by managing turn changes (Ford \& Thompson, 1996, Selting, 2005), marking a new topic, expressing agreement with the interlocutor, expressing intentions and facilitating the flow of discourse through pitch variation in backchannels ("mm-hm", "okay", "yeah") (Cole, 2015; Wennerstrom, 2001; Hellbernd \& Sammler, 2016). Importantly, prosody is one of many channels of information that are used in faceto-face communication to convey meaning. Prosody interacts with other communicative channels such as facial expressions, smiles, head nods, eyebrow movements and eye gaze to convey meaning (Swerts \& Krahmer, 2005, Cole, 2015, Kendon, 1980, McNeill, 1992, Flecha-García, 2010, Dijkstra et al., 2013). Across speakers, there is much variation in the use of prosody, which makes it a less reliable cue for meaning in interaction on its own (Hirschberg, 2002, Cole, 2015). Importantly, however, prosody is used and attended to by interlocutors to improve comprehension and plays a role in the building of meaning of face-to-face communication (Cole, 2015, Hellbernd \& Sammler 
2016). Interestingly, there are cross-cultural differences in the interpretation of and reliance on facial expression and intonational differences in conversation (Crespo Sendra et al., 2013).

Though prosody is believed to have a communicative function, it remains relatively understudied in aphasia (for a review of the literature, see Geigenberger \& Ziegler, 2001). Much research has focused on the hemispheric specialization for different prosodic features (Witteman et al., 2011), where the emphasis is on the difference between right and left hemisphere impairments and less on the influence of aphasia on the comprehension and production of prosodic features. Often, these studies do not specify whether or not their left-hemisphere impaired subjects include those with a diagnosis of aphasia or not. In the aphasiology literature, more research has been done on prosody in aphasic production than on comprehension of prosodic cues. Even less work has been done on the contribution of prosody to comprehension in conversation. A number of studies has attempted to describe the different characteristics of prosody in the production of subjects with fluent and non-fluent aphasia. Generally speaking, some different aspects of prosody, though different for each aphasia type, have been shown to be relatively intact, while other aspects deviate from measures of control subjects, such as fundamental frequency (F0) and timing aspects of prosody (Beeke et al. 2009, Danly \& Shapiro, 1982, Rhys et al., 2013, Seddoh, 2000, Danly et al., 1983). The question that is most relevant for the current discussion, is not necessarily how prosody is different from healthy controls, but how much prosody contributes to the communicative effectiveness in aphasia, in comprehension and production. At the moment, the answer to this question is unclear. Different approaches have been used in the literature to attempt to find an answer. Walker et al. (2009) showed that PWA produced prosodic structures that were different from those produced by controls on a word and sentence production task. Crucially, the identification of the intended meaning in those utterances by naïve listeners was more difficult on the items produced by PWA compared to those produced by controls. A number of studies have reported on the compensatory use of prosody by PWA in communication, by applying conversation analysis to observations of spontaneous conversation. By combining the limited verbal output, ranging from a few words to lexically empty syllables, with variations in pitch and volume, non-fluent PWA have been shown to convey meaning. Examples are signalling a demand for attention, calling an addressee, expressing uncertainty, agreement, enthusiasm or appreciation, managing interaction and turn-taking and finally requesting for something to happen such as for someone to continue or stop guessing, or 
for the provision of information (Goodwin, 1995, 2000, Oelschlaeger \& Damico, 1998; Lind, 2007, Rhys et al., 2013, Beeke et al., 2007, 2009). Dogil et al. (1990) presented a case study of a PWA with fluent aphasia who compensated for his language impairment by effectively using unimpaired prosodic skills.

A small number of studies have looked at the comprehension of prosody in aphasia. Emotional prosody, for example on a prosody and facial expression matching task, is suggested to be relatively unimpaired in aphasia (Barrett et al., 1999; Pell \& Baum, 1997; Geigenberger \& Ziegler 2001, Perlman Lorch et al., 1998), though the opposite has also been reported (Pell \& Baum, 1997 Pell, 1998). In contrast, linguistic prosodic processing has been shown to be impaired in aphasia, such as the ability to recognise focus/emphasis on prominent entities in an utterance (Geigenberger \& Ziegler, 2001; Baum, 1998) and the ability to indicate whether a sentence is a statement or a question (Pell \& Baum, 1997, Seddoh, 2006, Perkins et al., 1996). Pell \& Baum (1997) showed that prosody recognition by PWA was impaired on linguistic stimuli that required the processing of syntactic/semantic as well as prosodic cues simultaneously. The authors argued that it was the processing of multiple linguistic cues which might have been beyond the PWA's cognitive capacity (Pell \& Baum, 1997). The above-mentioned studies have assessed the comprehension of prosodic structures in aphasia in a decontextualized, non-interactive setting. A different approach to assess the role of prosody in comprehension was taken by researchers who studied eye-gaze movements of PWA, who in turn observed spontaneous, dyadic conversations. Healthy controls were shown to shift their eye-gaze in anticipation of a change in turn, which is commonly predicted by lexicosyntactic information and prosody. As lexico-syntactic information increased healthy controls were shown to benefit more from variance in intonation in predicting upcoming turns. PWA did not show this reliance on intonation cues (Preisig et al., 2016). In conclusion, there is some support for the idea that PWA can utilise prosody in production to communicate effectively, though most of the support for this claim relies on observational research with non-fluent PWA. If and how fluent PWA use prosody to communicate effectively remains unclear. Whether or not PWA can use prosody to support comprehension in conversation, is also unclear. The findings so far indicate that the interpretation of multiple signals might be more difficult for PWA, which could suggest that PWA will not benefit from the presence of prosodic information in conversation. More research will have to be done to draw stronger conclusions. 
Although the use of a number of different modalities has been studied in aphasia, these studies are limited in their generalisability to face-to-face communication because they have been studied be established on the basis of (a combination of) either of these options:

\section{Pre-existing}

1. Communal common ground: Communal common ground refers to shared beliefs and knowlin isolation from other modalities and their use is not studied in an interactive setting. Systematic analyses of the advantage of communicating through multiple channels, verbal and non-verbal, should be executed to better understand how linguistic impairments influence face-to-face communication.

\subsection{Language use is based on common ground}

Finally, communication in a real world setting allows interlocutors to rely on context during the exchange (Clark, 1996). Defining context is a difficult task, because the concept is inherently all-encompassing (Meteyard \& Vigliocco, in press). In order to make any claims or predictions regarding the influence of context, however, it is imperative to separate context into a number of (measurable) components. Clark (1996) refers to context for situated language use as common ground: the set of shared knowledge, beliefs and assumptions that exists between two speakers. Common ground is based on the idea that for people to be able to communicate, they have to understand each other: only when both speakers implicitly or explicitly agree that they understand each other, can conversation continute. When two interlocutors do not understand each other, conversation breaks down, or is shifted to a different topic. For example, if one speaker says "my dogs", both participants have to make sure they share the belief that this refers to the speaker's feet, rather than his canine friends, for conversation to be successful (Clark \& Brennan, 1991). If the addressee hasn't understood, for example because he doesn't share the knowledge of this particular reference, both parties have to work together to make sure sufficient mutual understanding is achieved to continue the conversation. According to Clark (1996), everything that is understood by two interlocutors engaged in conversation is part of their common ground. Common ground can edge based on a shared nationality or religion. Customs that are specific to a certain country or culture, will be shared and readily understood between people from that culture. 
2. Personal common ground: Personal common ground reflects the number of shared experiences two participants have had together, also referred to as the level of acquaintedness or familiarity.

Discourse representation

3. Situational context: what is physically present in the perceptual environment.

4. Communicative context: what has been referred to earlier in conversation (through any modality).

The main premise is that whatever is part of common ground will require less effort (time and/or energy) to refer to during communication (Clark, 1996, Horton \& Gerrig, 2005; Boyle et al., 1994, Smith et al. 2005). This means that the more common ground two interlocutors share, the greater the ease becomes with which they can communicate. For example, when an interlocutor refers to a new object, person or event during conversation, s/he will have to produce an elaborate utterance to ensure the addressee understands who or what is referred to ('the lady who helped me select a new pair of glasses in the store yesterday'). If the referent is already part of common ground of the interlocutors, for example because it was already part of the conversation at an earlier time (i.e. part of the discourse environment), because the addressee was present in the store the day before (i.e. part of a shared experience, or part of personal common ground) or the lady is physically present (i.e. part of the perceptual environment), the speaker can assume the information is 'given' and can use a less elaborate utterance to refer to the same concept ('the shop assistant', 'the lady', 'her' or even just point at the lady, if she's in the same physical space). With sufficient common ground, speakers can thus rely on the 'givenness' of information in dialogue and produce shorter, less informative and less 'complete' utterances (Bard et al. 2014). Comprehenders, in turn, can rely on context to restrict the number of possible interpretations for those utterances (in the context of a discussion about the purchase of a new pair of glasses, 'the lady' does not refer to any possible female person, but to the lady who both speakers know assisted in the selection of the right pair of glasses) (Skipper, 2014). By relying on common ground in production and comprehension during interaction, the computational load for both processes is minimized.

A number of researchers have proposed that the ease with which information can be retrieved from common ground (i.e. accessibility or 'givenness' of the information) determines the relative involvement of cognitive processes such as memory to support production and comprehension during 
face-to-face communication Ariel, 1988, Gundel et al. 1993, Givón, 1983, Chafe, 1994, Zwaan, 2014 Robinson, 1995, Brown-Schmidt \& Duff, 2016, Horton \& Gerrig, 2005: Schwanenflugel et al., 1992). According to these researchers, information is more easily retrieved when it is directly available (i.e. present in the physical environment) compared to when it is not (i.e. based on a shared experience, stored in long-term memory) and it is easier to retrieve information about something that was recently discussed (i.e. in the same or previous utterance) compared to information that was mentioned a longer time ago (a previous paragraph or several minutes ago in discourse) (Ariel, 1988, 2001, Sanders \& Gernsbacher, 2004) (the term long-term memory is used here to contrast this to shorter-maintained memory systems. It is generally assumed that multiple memory systems are involved in the retrieval of information that is part of common ground, though it remains unclear which systems exactly (Brown-Schmidt \& Duff, 2016). According to Zwaan (2014), abstract concepts always require a certain dergee of involvement from long-term memory, as these concepts per definition do not have physical referents. Interestingly, the accessibility of information influences the effort involved in communicating (production and comprehension) the information during conversation (Ariel, 1988, Robinson, 1995, Zwaan, 2014, Meteyard \& Vigliocco, in press). For example, when speaking about objects or events available in the physical, perceptual environment (i.e. the here-and-now), the speaker is not required to encode all information linguistically, as much of this can be retrieved from the physical environment, for example by pointing at an object (i.e. "I live here/five kilometres Portugal" while looking and pointing at a map of Spain (Meisel, 1987, pg. 213 as quoted by Robinson, 1995; Zwaan, 2014). As the topic of discussion is further removed from the here-and-now (i.e. speaking about last year's Christmas party, or about a philosophical treatise, which has no reference in place or time), interlocutors are required to encode more information linguistically (or through other communicative means), as much less information can be retrieved from the physical environment. In short, the more accessible information in common ground is, the easier it is for interlocutors to use this information in communication. Common ground can thus reduce the computational load for production and comprehension during communication.

For the current discussion, it is interesting to ask how much interlocutors can use common ground, or the 'givenness of information' to their advantage during face-to-face communication: does research support the idea that interlocutors benefit from the presence of common ground and does it lighten the computational load of language production and comprehension in face-to-face communication? Indeed, research has shown that in non-brain damaged controls, interlocutors 
indeed keep track of what is part of common ground with specific speakers and use it to guide how they produce and understand language during conversation, for example by using more detailed descriptions when speaking to another person who doesn't share a particular piece of knowledge (Brown-Schmidt et al., 2015, Brown-Schmidt \& Hanna, 2011; Heller et al., 2012, Hanna et al., 2003 Schober \& Brennan, 2003). Many studies have been done to look specifically at the influence of different types of common ground. Therefore, each type of common ground will be discussed separately. Firstly, the effect of having shared past experiences with an interlocutor (i.e. communal or personal common ground) on face-to-face communication has already been discussed in section 3.1. in the context of conversation partner familiarity. This research shows that when people have more shared personal or communal common ground, this can indeed lead to more efficient communication.

Secondly, research supports the idea that speakers and listeners rely on the communicative context, i.e. what has already been said or communicated during conversation, to guide their own production and comprehension during interaction. For example, the production of certain words and sentences by one interlocutor, can influence the selection of words and sentence constructions the other. Speakers tend to express themselves in similar ways at the lexical, semantic and syntactic level (Branigan et al. 2000). Priming studies have shown that speakers, implicitly, tend to produce sentences and lexical items that are syntactically or lexically similar to those produced by their conversation partner (Branigan et al., 2000; Mahowald et al., 2016; Bock et al., 2007). Studies where participants work on a collaborative task have shown that subjects tend to converge on specific descriptions (e.g. describing a maze as paths between two points or as rows and columns, Branigan et al, 2000) and lexical expressions that refer to particular stimuli (e.g. 'the ice skater' for a specific tangram figure, insert refs). Non-brain damaged controls have also been shown to flexibly and successfully rephrase and restate talk of others or themselves during conversation, referred to as reported speech (Hengst et al. 2005, Myers, 1999). This effect across linguistic levels can make language production computationally less taxing, as the choice for a word or sentence structure is "to a considerable extent driven by the context and do not need to be a burden for the speaker (Pickering \& Garrod, 2004, pg. 15). Not only do interlocutors use the same lexical items or sentence structures, research has shown that when interlocutors work with the same stimuli on a collaborative task, they tend to converge on the same type of referring expressions for which they progressively use fewer words, require fewer turns and provide less content (reference to a 
tangram figure develops from 'a person who's ice skating, except they're sticking two arms out in

front' to 'the person ice skating, with two arms' to 'the ice skater', Clark \& Wilkes-Gibbs, 1986. Fussell \& Krauss, 1992; Isaacs \& Clark, 1987; Schober, 1993, Garrod \& Anderson, 1987, Brennan \& Clark, 1996; Horton \& Gerrig, 2005). The same effect was found for gestures: gestures became less complex, less informative, less precise, less elaborate when they were directed at an interlocutor with shared knowledge on the task Gerwing \& Bavelas, 2004, Mondada, 2007; Holler \& Stevens 2007). As the stimuli become part of common ground, the interlocutors thus can exert increasingly less effort to refer to the same entities. Crucially, common ground is constructed uniquely by two conversation partners. When, halfway through the task, one of the partners is replaced, the decrease in number of words, turns and content is reversed, i.e. efficiency decreases (Brennan \& Clark, 1996 Schober \& Clark, 1989, Wilkes-Gibbs \& Clark, 1992). In addition, listeners are slower to respond to the same established reference from a new speaker compared to the same utterance provided by the speaker who established the reference in the first place (Metzing \& Brennan, 2003). In fact, the repeated use of the same referring expressions is expected by listeners: they show surprise when speakers change their referring expression (Metzing \& Brennan, 2003), or ask questions to ensure the same entity is targeted (Garrod \& Anderson, 1987). This is in line with research that shows that listeners build up expectations about what is to come, based on what they have heard so far (Skipper, 2014). Similarly, research has repeatedly shown that the context of a sentence or a gesture restricts the number of possible expected meanings of a word Kutas \& Federmeier 2011; Skipper, 2014). This effect has also been shown at the level of text and discourse (for a review, see van Berkum, 2009), supporting the idea that the language system integrates word, sentence, discourse and common ground information in the interpretation of language (Kutas \& Federmeier, 2011). Research has shown that the recent discourse history can help subjects resolve temporal ambiguities and allows for the use of shorter references (for a review, see MacDonald et al., 1994). In short, during face-to-face communication, interlocutors can use the communicative context (what has been said/communicated before) to minimize the efforts made in production by (1) co-coordinating lexical items and syntactic structures with their conversation partner and (2) by relying on the 'givenness' of information, which allows speakers to use shorter, less complex utterances. Comprehension can also be facilitated by the communicative context, as discourse (1) restricts the number of possible interpretations of a word or expression and (2) allows listeners to predict what will be communicated next. 
Finally, research has also shown that the physical environment, or the referential situation, is also used to support production and comprehension during face-to-face communication Knoeferle \& Guerra, 2016). Lysander \& Horton (2012) and Clark \& Krych (2004) showed that communicative efficiency of their participants depended on the shared view of the task-relevant materials. Overall communication was more efficient when the materials were visually and referentially available to both participants compared to when they were not. In production, research has shown that healthy adults monitor their surroundings for non-linguistic ambiguity before speaking to ensure their utterance is informative in the current environment (Rabagliati \& Robertson, 2017). Speakers thus adapt their expressions during communication based on the visual availability of the objects they're describing to their conversation partners. For example, if only one out of two buckets is visually available to the addressee, speakers have been shown to use a less specific description such as 'the bucket', compared to when both objects are visually available to the addressee. The utterance then includes more detail to specifiy, for the addresseee, which bucket is referred to (i.e. 'the small bucket'; Yoon et al., 2012, Brown-Schmidt \& Duff, 2016). More support for the reliance on perceptually available information also comes from developmental research and studies second language (L2) learning. Children have been shown to develop the ability to change their referring expressions on the basis of the availability of information in discourse and perceptual availability of the referents for their conversation partners between the ages of 2 and 4 years old (Moll \& Tomasello, 2006: Matthews et al., 2006, Salomo et al., 2011). Furthermore, Children and L2 learners have been shown to acquire the ability to use displaced reference (i.e. reference to objects and events not currently present) later than reference to the here-and-now (Sachs, 1983). Research in second language learning has supported the idea that displaced reference is more effortful than speaking of the here-and-now, and that it requires increased linguistic complexity (Robinson \& Gilabert 2007: Robinson, 1995, Gilabert, 2007; Ishikawa, 2007). Indeed, when speaking of the here-and-now, people can point at, touch, exhibit and present physical objects to support communication (Clark 2005). Indirect evidence comes from research on the processing of concrete and abstract concepts: research has shown that it is easier for non-brain damaged controls to produce and understand concrete concepts compared to abstract concepts (Paivio, 1991; Evans et al., 2012, Roxbury et al. 2014). Though concreteness is not synonymous to visual or physical availability, concrete concepts are more tangible, have a higher imageability (i.e. it is easier to think of a mental image), higher contextual availability (i.e. it is easier to think of environments or contexts in the real world 
in which the objects could appear) and can be experienced through the senses (seeing, touching, etc), whereas more abstract concepts are less tangible, have lower imageability, lower contextual availability and are less often experienced through the senses as they often do not have real-world referents (Paivio, 1986, Schwanenflugel et al., 1992). According to Zwaan (2014), information regarding more abstract concepts requires the involvement of more long-term memory processes and the reliance on linguistic processing, which would be qualified as more effortfull.

Research has also provided support for the idea that the visual environment can affect and restrict the way (ambiguous) linguistic input is interpreted (Tanenhaus et al., 1995, Eberhard et al. 1995 Huettig et al., 2011, Chambers et al., 2002) and it can help predict what linguistic information is coming up next (Huettig et al., 2011, Skipper, 2014). Memory-impaired subjects with hippocampal amnesia who could not rely on common ground (information stored in memory) to resolve linguistic ambiguities were shown to use visual information to guide behaviour Rubin et al. 2011). It appears that the presence of referents in the visual environment can aid comprehension by limiting the possible interpretations of the linguistic information, i.e. reducing the computational load during comprehension, as long as an element of what is discussed refers to the visual environment.

In aphasia, less research has been done on the use of common ground in communication. Again, the effect of familiarity or shared personal and communal common ground has been discussed in section 3.1. Though the use of the communicative context in interaction has not been studied extensively, there is evidence to support the idea that PWA benefit from having a communicative context to build their own expressions on and to aid comprehension. As for non-brain damages controls, PWA have shown responsiveness to priming effects at the lexical level: hearing or reading a word can make it easier to produce a semantically related or identical target word in picture naming tasks (Renvall et al., 2003, Cornelissen et al., 2003, Renvall et al., 2007). A similar facilitatory effect resulted from the presence of a semantic-syntactic environment (i.e. "social exclusion" for the word "exclusion") on a word repetition task (McCarthy et al., 2017). The responsiveness to this kind of context has been shown to depend on the nature of the impairment: if the underlying impairment is more phonological in nature, contextual phonological cues will be more beneficial. If the impairment is more semantic in nature, semantic cues (such as "social exclusion" for "exclusion") will have more of a facilitative effect (Martin \& Laine, 2000; Martin et al., 2004). Similar priming effects have also been shown for syntactic structures: PWA were increasingly likely to produce specific syntactic 
structures after hearing them during a picture description task (Saffran \& Martin, 1997, Cho-Reyes et al. 2016, Rossi, 2015, Hartsuiker \& Kolk, 1998). In addition, sentence-level intervention based on priming mechanisms have shown to improve picture description sentences in PWA (Mack et al. 2017: Lee \& Man, 2017, Weinrich et al. 2001). Priming is automatic and is hypothesized to lead to greater availability of a lexical item or syntactic structure, which then results in a lower demand on processing resources for word or sentence production. Whether PWA can benefit from priming in face-to-face communication has not been studied yet. In addition to automatic priming effects, a small number of studies has suggested that reported speech, i.e. the conscious repeating of output from a conversation partner to produce a similar syntactic structure or lexical item, is used by some PWA in everyday interactions (Hengst et al. 2005). Despite the high number of errors and failed attempts to repeat complete utterances, reported speech has been shown to contribute to successful communication in aphasia. In a case study, Oelschlaeger \& Damico (1998) showed that the explicit repetition of the conversation partner's utterances enabled one PWA to achieve conversational goals (i.e. expressing agreement, uncertainty, etc.) that would otherwise not have been possible due to his very limited spontaneous verbal abilities. Not only does the presence of a communicative context directly influence comprehension and production processes during communication, PWA can also use information that was discussed earlier during interaction to build common ground with their conversation partners. Like non-brain damaged controls PWA have been shown to use increasingly fewer turns and shorter, more simplified references during a collaborative referencing task with familiar conversation partners (Hengst, 2003 , Meuse \& Marquardt, 1985). This supports the idea that PWA can rely on common ground and produce increasingly shorter, less complex utterances to refer to 'given' information during interaction. Finally, the presence of a communicative context has also been shown to support comprehension in aphasia: strongly predictive sentence contexts have been shown to facilitate lexical retrieval and production in PWA (Warren et al., 2016; Love \& Webb, 1977, Dickey et al. 2014), though this effect is slower compared to non-brain damaged controls. Similarly, PWA showed an N400 effect like non-brain damaged controls when hearing a semantically unexpected word in a sentence, though this effect is less pronounced and delayed in aphasia (Khachatryan et al., 2017; Swaab et al., 1997; Hagoort et al., 1996). PWA were also able

to, implicitly, predict upcoming syntactic structures based on the context of the sentence Hanne et al. 2015a b). Having a communicative context which limits the number of possible meanings of an utterance, and on which production can build, rather than having to stand alone, can thus 
alleviate come of the processing demands involved in production and comprehension. It is not known whether PWA can benefit from this type of context during face-to-face communication. Conversation Analysis on exactly this process has shown that, in a more general sense, PWA use the communicative context (i.e. its sequential context) as a resource to construct their turns during conversation and comprehend what others communicate (Beeke et al., 2007).

Finally, even less is known on how the referential context, or the physical environment can influence in face-to-face communication in aphasia. In clinical practice, PWA are trained to compensate for their language loss by pointing to objects in the physical environment, if possible, to support communication. An observational study by Howe et al. (2008) indicated that the availability of a physical referent in the environment can facilitate communication in real world settings. Visual information in the form relevant, contextualized photographs, or a tv program showing a specific setting that clearly show situations, places, experiences and people, graphic topic setters and photographic communication books have been shown to facilitate reading comprehension (Dietz et al. 2013 ) as well as communication in aphasia (Howe et al. 2008), leading to longer conversation durations and exchange of more content and increased number of exchanges (Garrett \& Huth, 2002 Hux et al., 2010, Beukelman et al., 2015; Ho et al., 2005: Ulmer et al., 2016). The use of such contextually rich photographs or videos is hypothesized to facilitate communication because it creates a shared communication space that includes content and background information that the PWA can refer to in support of comprehension and expression (Hux et al., 2010; Beukelman et al. 2015: Ho et al., 2005; Howe et al., 2008). The presence of a shared communication space through photographs is comparable to having a referential context during communication, in the sense that not all information has to be retrieved from memory (computational demands are lightened) or to be coded linguistically, because the information is visually available (Beukelman et al., 2015, Dietz et al. 2009). Such a visual environment can provide PWA with the ability to refer to objects in communication, which can reduce the processing demands of speaking. Howe et al. (2008) also suggested that the familiarity of a setting or particular physical environment can influence the ease with which the PWA can rely on this during communication. In line with the literature on nonbrain damaged controls, research on aphasia has also shown that it is easier for PWA to process concrete words compared to abstract words (Sandberg \& Kiran, 2014, Alyahya et al., 2018). As discussed above, this provides indirect support for the idea that objects that are more likely to have real-world referents (i.e. can be pointed at, drawn, etc) are easier to understand and name 
compared to objects that are less likely to have real-world referents.

\subsection{Interim summary}

In short, there is empirical evidence to support the proposed model of situated language use: when language is used in its natural environment, it becomes an interactive, multimodal and contextual phenomenon (see Table 1 for an overview of the components discussed in this paper). These three characteristics interact during the overall communication process. When studying language in use, the influence of these three components thus needs to be investigated or controlled for. A measure that does not take into account all three components should not claim to capture situated language use or communication as such. The linguistic impairment in aphasia is, as discussed before, relatively well-understood. How this impairment interacts with the components of language use as discussed in this paper, however, remains largely unknown and understudied. Critically, any therapeutic intervention that targets situated language use (functional communication) will also need to incorporate the principles outlined above.

\section{Cognitive mechanisms underlying language use}

Natural language use is a complex phenomenon that requires a multitude of skills. The abovementioned model clearly breaks down situated language use into different behavioural components. Consequently, it becomes possible to outline which cognitive skills (linguistic and non-linguistic) are most likely involved for each behavioural component of situated language use. A thorough review on what is currently known about the cognitive mechanisms underlying situated language use is beyond the scope of this article. This section gives a brief idea of the existing work on this topic.

\subsection{Monitoring}

The precise relationship between self-monitoring during communication and linguistic skills is still unclear. Different theories exist about the way self-monitoring is accomplished. A number of studies directly link monitoring to linguistic skills such as comprehension and production: monitoring may be achieved through the comprehension system, whereby one 'listens' to one's own speech (post-articulatory monitoring), or through the production system, where one monitors the output before it is produced (pre-articulatory monitoring) Postma (2000); Levelt (1989); Marshall 


\begin{tabular}{|c|c|c|}
\hline Components & Definition & Sub-components \\
\hline Interactive & $\begin{array}{l}\text { Joint activity between two } \\
\text { people. } \\
\text { Actions of one person de- } \\
\text { pend on those of the other }\end{array}$ & $\begin{array}{l}\text { - Feedback / backchannels } \\
\text { - Co-construction of dialogue } \\
\text { - Familiarity }\end{array}$ \\
\hline Multimodal & $\begin{array}{l}\text { Multiple interdependent } \\
\text { channels of communication } \\
\text { are available and integrate } \\
\text { into a single composite } \\
\text { message. } \\
\text { Different channels replace, } \\
\text { supplement, complement } \\
\text { and emphasize speech. }\end{array}$ & $\begin{array}{l}\text { - Language } \\
\text { - Prosody } \\
\text { - Gesture } \\
\text { - Facial expressions } \\
\text { - Body posture }\end{array}$ \\
\hline $\begin{array}{l}\text { Contextual } \\
\text { (relies on } \\
\text { common } \\
\text { ground) }\end{array}$ & $\begin{array}{l}\text { Common ground provides } \\
\text { interlocutors with context } \\
\text { that allows them to as- } \\
\text { sume a degree of "givenness" } \\
\text { of information, or directly } \\
\text { use physical referents dur- } \\
\text { ing communication. This } \\
\text { relieves the communicative } \\
\text { burden. }\end{array}$ & $\begin{array}{l}\text { Pre-existing: } \\
\text { - Communal common ground } \\
\text { - Personal common ground } \\
\text { Discourse representation: } \\
\text { - Situational context } \\
\text { - Communicative context }\end{array}$ \\
\hline
\end{tabular}

Table 2: The key components that characterize language in use (based on Clark. 1996). 
(2006). While some studies report a relationship between comprehension or production skills and self-monitoring, a possible dissociation between these variables has also been reported in PWA, i.e. that comprehension or production is impaired while self-monitoring remains intact Nickels \& Howard, 1995, Marshall, 2006, Marshall et al., 1998, Schlenck et al., 1987). Some have suggested that such a dissociation might be due to a strategic choice rather than a linguistic impairment: PWA might strategically be focused more on one type of monitoring, for example via the comprehension system rather than the production system, because the chance of correctly repairing a detected error might be so low that it becomes beneficial to focus on the system that has bigger chances of successfully detecting and repairing errors (Nickels \& Howard, 1995). This would explain the differences in monitoring between PWA, despite having similar profiles of comprehension or production. A different suggestion is that in addition to impaired linguistic skills, other cognitive, non-linguistic impairments might also play a role Nickels \& Howard (1995). Models of self-monitoring during language production specify the involvement of an articulatory buffer, i.e. working memory, that holds linguistic content (Levelt et al. 1999). It is likely that working memory is involved, in order to hold information in mind while it is checked against an internal representation. Sub-components of executive functioning have been associated with self-monitoring and other-monitoring such as attention (Postma, 2000, 1997, 2002, Levelt, 1992) as well as working memory and cognitive flexibility (Diamond, 2013). In healthy adults, higher task demands, such as performing a dual task, have been shown to negatively influence monitoring (Postma, 2002), suggesting that monitoring relies on a limited resource. More research is still needed to find out how monitoring is affected in PWA, and what the underlying mechanisms are.

\subsection{Multimodal communication}

The use of different modalities as a compensatory strategy during production, i.e. the use of one modality such as gesture when another modality such as language, is difficult, has been related to a number of underlying cognitive skills. There is evidence to suggest that cognitive control is involved in a person's ability monitor one's own behaviour and detect problems in message transmission, to evaluate alternative methods of communication and/or to switch to another modality (Purdy, 2002). A number of studies have found switching impairments in PWA (e.g., Frankel et al. 2007, Chiou \& Kennedy 2009, Hachioui et al. 2014; Wall et al. 2017 as well as generation and selection of appropriate strategies (Frankel et al., 2007), both skills that are highly relevant when trying 
to switch from one modality to the next. Executive functioning has been linked to successful use of augmentative and alternative communication (AAC) (Nicholas et al., 2005, 2011), while impaired executive functioning has been related to lack of switching between modalities during communication, despite having learned to use different modalities separately (Purdy et al., 1994).

In order to benefit, in comprehension, from the presentation of information through different modalities, one has to be able to integrate information from those different channels, or select and combine specific subset of channels, while ignoring others. In healthy adults, there is evidence to suggest that when cognitive demands of a specific task are high, i.e. require focus of attention on one task, other channels of information might not facilitate performance, simply because there are not sufficient cognitive resources available to attend to all sources of information Lysander \& Horton, 2012). For PWA, a number of studies have suggested that the processing of multiple cues might be beyond the PWA's cognitive capacity (Pell \& Baum, 1997; Preisig et al., 2015) and the integration of different channels to aid comprehension might be impaired (Cocks et al., 2009). What cognitive mechanisms exactly underlie the processing and integration of multimodal information is still unclear: Whether this is affected by deficits or limited capacity of attention, impaired working memory capacity, or other executive control functions such as inhibition, which has been shown to be impaired in PWA (Frankel et al., 2007), is not yet well-understood. Further research is needed to better understand the influence of multiple sources of information on comprehension in PWA.

\subsection{Common ground}

As was discussed in section 3.3 , the use of common ground can minimize the amount of processing required for communication. In healthy adults, as argued by (Clark, 1996), interlocutors will work to minimize effort during communication by all possible means. Minimizing effort is important because humans only have a limited capacity to process information. A number of theories posit that language processing can be impaired due to a change in the allocation or distribution of more general attention- or cognitive processing resources in PWA (McNeil et al., 1991, Murray, 1999, Hartsuiker \& Kolk, 1998, Hula \& McNeil, 2008). According to these theories, there is a general capacity-limited system of attentional or processing resources in the brain (also referred to as effort, energy or activation) (Kahneman, 1973). The amount of resources required to execute a specific task depends, according to this theory, on the specific task demands. Someone will fail to complete a task when: (1) the task demands exceed the available capacity, (2) the available resources are wrongly 
allocated or (3) the resources are allocated inefficiently, i.e. allocation is too slow (Murray, 1999). In line with this, an important role of long- and short term memory capacity for communication has been suggested by a number of researchers (Zwaan, 2014, Brown-Schmidt \& Duff, 2016, Horton

\& Gerrig, 2005, Schwanenflugel et al., 1992), especially for conversations that are further removed from the concrete, here-and-now. The exact underlying processes still remain unknown, however.

For comprehension, communicative context has been shown to reduce the number of alternative interpretations (Kutas \& Federmeier, 2011; Skipper, 2014). Working memory capacities have been argued to mediate differences in comprehension, as people with larger working memory capacities are able to hold more alternative interpretations in mind and compare them (Just \& Carpenter, 1992). The use of common ground and the collaboration with one's interlocutor during communication, for example when introducing new information to the conversation, is said to depend on the availability of sufficient cognitive resources and are subject to disruption when mental resources are limited (Pickering \& Garrod, 2004, Roxnagel, 2000, Bard et al., 2000).

There is research to support the idea of a slowed down processing of information in PWA (e.g. Swaab et al., 1997, Swinney et al., 2000), and an increase in error rates when task demands increase (for example, on a dual task; Heuer \& Hallowell, 2015), providing support for the limited cognitive capacity system theory. In line with this idea, information theory, which originated from mathematics and engineering as a way of quantifying information or message complexity, has been applied to psycholinguistics to investigate processing cost in linguistic information during communication. Information theory has also been used to show a reduced processing capacity in PWA (van Ewijk \& Avrutin, 2016; van Egmond et al., 2015). Together, these studies suggest that a general system of cognitive resources is functioning differently for PWA due to the brain damage, and this in turn affects communication.

The referential context, i.e. the physical environment, can also be used strategically during communication, for example by referring or pointing to objects that are visible to both interlocutors, instead of verbally naming the object. This process requires a number of cognitive skills such as the ability to detect the need to transmit a message differently, an awareness of one's surroundings and the ability to visually search the environment and select a suitable physical referent. If the object is less concrete, or not available in the immediate physical environment, the interlocutor can scan his/her surroundings for a related object that might help their addressee figure out the target word. This, in turn, requires the ability to dynamically scan and evaluate objects for their 
appropriateness against the target concept. Research has shown that visual search of the physical environment requires the involvement of cognitive processes such as working memory, multiple types

\subsection{Interim summary}

This section has given an idea of the different types of linguistic and non-linguistic cognitive skills that are required for successful communication. This likely includes a number of sub-components of executive functioning (cognitive flexibility, switching and inhibitory control), attention and memory (long-term and working memory). In addition to this, the amount or complexity of the information that is processed, i.e. the task demands, seem to influence language performance. Each cognitive function (executive function, attention, working memory) can be broken up into a multitude of subcomponents that each can be differentially associated with processes of language use (for example, as discussed in relation to attention by Murray, 1999, or here in relation to executive function by Diamond, 2013). Importantly, however, research has shown that in PWA, a number of these nonjinguistic cognitive mechanisms are often impaired (Hachioui et al., 2014, Murray, 2012, 1999, Chiou \& Kennedy, 2009). Furthermore, impaired non-linguistic cognitive functions have been associated with particular symptoms experienced by PWA and to their situated language use (Hachioui et al. 2014 Murray, 2012, Helm-Estabrooks, 2002). Although the importance of taking into account non-linguistic impairments has been underlined in the aphasiology and rehabilitation literature, it often remains unclear what the exact relationship is between all the factors involved in language use. Hopefully, the use of the proposed model will help tease the different factors apart. More research is warranted to gain a better understanding of the intricate relationship between the sub-components of language use and the underlying cognitive mechanisms in aphasia.

\section{Discussion}

\subsection{Overlap between measures of functional communication and the proposed model}

A first step in applying this described model of situated language use to aphasia, is to evaluate to what degree current measures of functional communication already incorporate the three key components of the model. The aim of the current model is to first provide the theoretical foundations for an objective measure of situated language use in aphasia. With the model and this requirement in mind, a number of instruments can already be eliminated. Of the instruments reviewed in this 
paper, most of the instruments in the category linguistic analysis of connected speech do not include all three components from the model. Most measures focus only on the linguistic modality (speech) and leave out non-verbal information, thus not meeting the multimodal requirement (CU, Yorkston \& Beukelman, 1980, CIU Nicholas \& Brookshire, 1993 IU, McNeil et al., 2001). Though the Pragmatic Protocol (Prutting \& Kirchner, 1987) does take into account most of the model's components in a face-to-face communicative setting, it is set up to judge the appropriateness of specific pragmatic characteristics in conversation, rather than to quantify the effectiveness of communication, or describe how communication is achieved. Ramsberger \& Rende (2002) measure of transactional success comes close to ticking all the boxes (semi-spontaneous re-telling of I love Lucy video), but the procedure is quite long and relies on the shared knowledge of I Love Lucy videos, which is much more difficult to standardize or control for in different clinical settings. Conversation analysis focuses on directly observed face-to-face communication and explicitly takes into account the interactive, joint responsibility of communication and many of the multimodal ways in which interlocutors communicate. This method provides a lot of insight into the processes that facilitate and impede conversational success. Due to its observational nature, it is difficult to generalise findings from CA alone to a general theory of communication in aphasia (but see Barnes \& Bloch, 2018)).

A number of the observational profiles that are rated by the PWA or a proxy and those rated by the clinician take into account the multimodal and interactive components of situated language use. However, many items on most of these profiles refer to communication in different settings (i.e. group conversations, email, watching TV, speaking on the phone). Performance across different settings will probably vary. Using an overall score will average out the strengths and weaknesses for each setting, including the 'baseline' measure of face-to-face communication (see below). In addition, for a number of the observational profiles, communication is judged on the basis of indirect observation (i.e. memory of multiple conversations that have previously been observed), rather than directly observing and scoring behaviour (all of the patient or proxy rated instruments, as well as the FCP, Sarno, 1969 and the ASHA FACS, Frattali et al., 1995). The criticism for observational profiles in general has already been discussed elsewhere in this paper. The profiles that are rated by the PWA themselves or a proxy are very useful in assessing the difference between subjective judgments of communication compared to more objective measures.

Finally, of the standardized tests, the CADL-2 (Holland et al., 1999) does not take into account 
the interactive aspect of communication, while the ANELT (Blomert et al., 1994) does not measure multimodal communication. This leaves the Scenario Test (van der Meulen et al., 2010). While at face value, the Scenario Test assesses multimodality and interactivity in a face-to-face setting, some drawbacks apply: the use of role play requires PWA to pretend to be in a different time or place without actually being in that specific setting. This is, arguably, an inherently different situation compared a setting in which both parties spontaneously communicate. Role-play potentially increases cognitive demands that would not be required in the real-life equivalent (Ramsberger, 1994 Wirz et al. 1990), not in the least because it requires interlocutors to discuss the here-and-now without the support of a full-fledged referential situation (though props are used to provide PWA with some physical referents). Whether or not this drawback is significant enough to reject the Scenario Test as an appropriate instrument according to this model, is still unclear. Out of all the instruments that have been discussed in this paper, the Scenario Test (van der Meulen et al., 2010) seems to come closest to an appropriate measure of situated language use in aphasia, according to the proposed model. Further research on how each of the model's components (interaction, multimodality and common ground) influence communication in aphasia will provide insight into their relative importance during situated language use. With such knowledge, the existing instruments can be judged on the degree to which they take the most important components into account.

Finally, it is imperative that in addition to measuring the ability to use language in situ, the cognitive abilities of the PWA are measured and the relationship between these skills (and their sub-components) are identified. Only then will it be possible to predict responsiveness to treatment and a possible therapy outcome at the level of everyday communication.

\section{Conclusion}

Language has traditionally been studied as a decontextualized, solely linguistic process. Researchers have, over the past few decades, realized that this traditional approach does not allow us to better understand the way language functions when it is used in the real world, for communication. This is true for language research in general, as well as for those studying aphasia specifically, where an increasing interest in functioning and intervention at the conversational level is found. To better understand how language is used in everyday life, i.e. how effective communication is achieved in a naturalistic environment, the challenge is to identify the variables that are involved in this process and to assess their impact on the communication process. 
In this paper, a structured, theoretically founded approach to studying communication is proposed. A model of communication, as summarized in Table 2, is derived from a wealth of studies 2018). The model delineates three major components, which in turn can be broken up into different internal and external factors that each can independently influence communication. The 
internal factors, such as the different cognitive skills required for communication (linguistic and

non-linguistic), can be differently impaired in each person, resulting in a different overall communication profile for each PWA. This profile will, in turn, interact differently across various external factors such as different conversation partners, different settings and contexts that may be more or less supportive for communication. The current model suggests that the aim of quantifying a person's ability to 'use language' in a single number would not capture this variability. The aim of an instrument of communicative ability should thus be to compile a profile of skills and define how this profile might interact with different external variables. Note that this is, in a way, similar to how a number of aphasia batteries work, when providing scores across different component linguistic skills.

Secondly, the model prescribes the setting in which research on communication, and the relationship between internal and external factors, should be carried out. Instead of assessing the influence of the components of language use across an infinite number of different settings, such a speaking on the phone, sending an email or text message, or speaking face-to-face, it has been suggested that to evaluate the principles that govern situated language use, one can start by studying the most basic form: face-to-face communication (Barnes \& Bloch, 2018; Clark, 1996, McDermott \& Tylbor, 1983, Pickering \& Garrod, 2004, Bavelas \& Chovil, 2000), as it is the most commonly used and pervasive form of communication, it is universal to all human societies, it is the basis for typical language acquisition in children and it does not require education or special skills (Bavelas \& Chovil, 2000 Clark, 1996). Indeed, Davidson et al. (2008) showed that face-to-face conversation is the most frequently occurring communicative activity in daily life for PWA. Once the principles that govern face-to-face communication are teased out, language use in other communicative situations, such as speaking on the telephone, can be derived from the basic face-to-face exchange (Clark 1996). A discussion of the specific features that distinguish face-to-face communication from other situations in which language is used is beyond the scope of this article (for a detailed description see Clark, 1996). For the current purposes, it is important that we already have a theoretically founded argument for identifying universal principles of communication in face-to-face communication.

Thirdly, the current model is based on the assumption that situated language use represents an inherently different task, with different task demands, compared to the processing of decontextualized, linguistic information. In addition to this, we now know that language only represents 
a single component in a complex system of skills required for communication, and the intricate synchronization of skills during communication only makes language use that much more complex. If we accept these assumptions, it should be relatively unsurprising that the field has struggled to find generalization of therapy effects to situated language use (aka functional communication). If we know that language use does not just require linguistic skills, but the integrated use of linguistic skills with many other cognitive skills, in different environments, a logical question to ask is why any SLT intervention is predominantly aimed at working with language materials that are taken out of the context in which they are used or encountered in everyday life. The generalization of linguistic skills to everyday language use will require more than solely training the linguistic impairment. It might be necessary to train a set of communication skills that look very much like strategies or meta-cognitive abilities (e.g. monitoring, checking). Though many different 'conversational' therapies exist, surprisingly few focus on training conversational skills with the PWA (Simmons-Mackie et al. 2014). In order to relearn how to walk, giving someone a rigorous gym protocol to strengthen one's leg muscles will probably not suffice. The muscles must also learn how to coordinate their actions to walk, jump, and climb the stairs again. The current model underlines the importance of assessing the interaction of various components, including language skills, on effective language use, and the importance of focusing on conversation and communication as a whole in therapy, in which language skills interact with other skills required for efficient language use. We would like to note here that in our informal conversations with Speech Language Therapists, they often report working in this way - i.e. targeting everyday communicative behaviours. However, in our opinion, the research literature does not properly reflect that work.

Finally, it is important to note that within this model, it is possible to take into account both functions of communication: the transactional function, i.e. 'getting the message across', as well as the interactional function of communication, which refers to the expression of social relations, personal attitudes and social affiliation through language (Brown \& Yule, 1983), such as "greetings, brief comments and asides, expressions of affection and concern, an affirming gesture" (Davidson et al. 2003, p. 257). The importance of the latter function of communication, especially for people with aphasia, has been emphasized in the past, while previous research and many existing instruments that measure language use have often been criticized for focusing solely on the transaction, or for their inability to capture the interpersonal, interactional aspects of communication Davidson 
et al. 2003 Simmons, 1993, Simmons-Mackie \& Damico, 2001). By moving away from a sole focus on language, and by including both the multimodal and interactive aspects of communication, the proposed model of situated language use makes measurement of both functions of communication possible. Although the authors acknowledge the importance of assessing the impact of the language impairment on the PWA's well-being and level of participation, the aim of this model is to narrow down what situated language use is and how it is impaired in aphasia. Once language use is more clearly defined and described in aphasia, the relationship between the linguistic impairment (language in vacuo), the impairment at the level of language use and the impact of these on the level of participation and well-being can be explored more easily.

1320

To conclude, we have presented a systematic, theoretically founded approach to studying situated language use in aphasia. We have reviewed current assessments and the available research literature against this preliminary model. It provides a clearly delineated set of components that are involved in language use, which can be used in future research to further dissect the influence of each component on communication. To better inform our therapies aimed at improving communication, we need a better grasp on what it is, which skills are required to communicate efficiently and to know how therapies should be designed so that they target language in situ.

\section{Acknowledgements}

We would like to thank Prof. Herbert Clark and Dr. Arpita Bose for helpful comments on an earlier version of this manuscript. We would also like to thank our colleagues at the School of Education, Communication and Education Sciences, Newcastle University and our colleagues who attended the British Aphasiology Society Research Update Meeting 2018 for their invaluable input and feedback. 


\section{References}

Baum, S. (1998). The role of fundamental frequency and duration in the perception of linguistic stress by individuals with brain damage. Journal of Speech, Language 83 Hearing Research, 41, 31.

Bavelas, J., \& Chovil, N. (2000). Visible acts of meaning: An integrated message model of language in face-to-face

Bavelas, J., Coates, L., \& Johnson, T. (2000). Listeners as co-narrators. Journal of Personality and Social Psychology, $79,941-952$. doi $10.1037 / 0022-3514.79 .6 .941$

Bavelas, J., Coates, L., \& Johnson, T. (2002). Listener responses as a collaborative process: the role of gaze. Journal of Communication, 52, 566-580. 
Beckley, F., Best, W., \& Beeke, S. (2017). Delivering communication strategy training for people with aphasia: what is current clinical practice? Int J Lang Commun Disord, 52, 197-213. doi 10.1111/1460-6984.12265

Beeke, S., Maxim, J., Best, W., \& Cooper, F. (2011). Redesigning therapy for agrammatism: Initial findings from the ongoing evaluation of a conversation-based intervention study. Journal of Neurolinguistics, 24, 222-236. doi $10.1016 / j \cdot$ jneuroling.2010.03.002

Beeke, S., Maxim, J., \& Wilkinson, R. (2007). Using conversation analysis to assess and treat people with aphasia. Semin Speech Lang, 28, 136-47. doi 10.1055/s-2007-970571

Beeke, S., Wilkinson, R., \& Maxim, J. (2009). Prosody as a compensatory strategy in the conversations of people with agrammatism. Clin Linguist Phon, 23, 133-55. doi 10.1080/02699200802602985.

de Beer, C., Carragher, M., van Nispen, K., Hogrefe, K., de Ruiter, J. P., \& Rose, M. L. (2017). How much — information do people with aphasia convey via gesture? Am J Speech Lang Pathol, 26, 483-497. doi 10.1044/ 2016_AJSLP-15-0027

van Berkum, J. (2009). Semantics and pragmatics: From experiment to theory. chapter The neuropragmatics of 'simple' utterance comprehension: An ERP review. (pp. 276-316). Basingstoke: Palgrave Macmillan.

Beukeboom, C. (2009). When words feel right: How affective expressions of listeners change a speaker's language use. European Journal of Social Psychology, 39, 747-756. doi 10.1002/ejsp.572

Beukelman, D., Hux, K., Dietz, A., McKelvey, M., \& Weissling, K. (2015). Using visual scene displays as communication support options for people with chronic, severe aphasia: A summary of AAC research and future research directions. Augmentative and Alternative Communication, 31, 234-245. doi 10.3109/07434618.2015.1052152

Birdwhistell, R. (1970). Kinesics and context: Essays on body motion communication.. Philadelphia: University of Pennsylvania.

Bloch, S., \& Beeke, S. (2008). Co-constructed talk in the conversations of people with dysarthria and aphasia. Clin Linguist Phon, 22, 974-90. doi 10.1080/02699200802394831

Blomert, L., Kean, M., Koster, C., \& Schokker, J. (1994). Amsterdam-nijmegen everyday language test - construction, reliability and validity. Aphasiology, 8, 381-407.

Blomert, L., Koster, C., Mier, H. V., \& Kean, M.-L. (1987). Verbal communication abilities of aphasic patients: the everyday language test. Aphasiology, 1, 463-474. doi 10.1080/02687038708248873

Bock, K., Dell, G., Chang, F., \& Onishi, K. (2007). Persistent structural priming from language comprehension to language production. Cognition, 104, 437-458. doi https://doi.org/10.1016/j.cognition.2006.07.003

Bolinger, D. (1986). Intonation and its parts: melody in spoken English. Stanford University Press.

Booth, S., \& Perkins, L. (1999). The use of conversation analysis to guide individualized advice to carers and evaluate change in aphasia: a case study. Aphasiology, 13, 283-303. doi 10.1080/026870399402109 
Boyle, E., Anderson, A., \& Newlands, A. (1994). The effects of visibility on dialogue and performance in a cooperative problem solving task. Language and Speech, 37.

Brady, M. C., Godwin, J., Enderby, P., Kelly, H., \& Campbell, P. (2016). Speech and language therapy for aphasia 1400

after stroke: An updated systematic review and meta-analyses. Stroke, 47, E236-E237. doi 10.1161/Strokeaha. 116.014439

Branigan, H., Pickering, M., \& Cleland, A. (2000). Syntactic co-ordination in dialogue. Cognition, 75, B13-B25. doi https://doi.org/10.1016/S0010-0277(99)00081-5

Brennan, S., \& Clark, H. (1996). Conceptual pacts and lexical choice in conversation. Journal of Experimental

1. Psychology: Learning, Memory and Cognition, 22, 1482-1493. doi http://dx.doi.org/10.1037/0278-7393.22. 6.1482

Brown, H. P. . O. L., C.M. (1999). The neurocognition of language. chapter The neurocognition of syntactic processing. Oxford: Oxford University Press.

Brown, Y., \& Yule, G. (1983). Discourse Analysis. Cambridge Textbooks in Linguistics. Cambridge: Cambridge University Press.

Brown-Schmidt, S., \& Duff, M. (2016). Memory and common ground processes in language use. Topics in Cognitive Science, 8, 722-736. doi $10.1111 /$ tops.12224

Brown-Schmidt, S., \& Hanna, J. (2011). Talking in another person's shoes: Incremental perspective-taking in language processing. Dialogue \& Discourse, 2, 11-33. doi 10.5087/dad.2011.102.

Brown-Schmidt, S., Yoon, S., \& Ryskin, R. (2015). People as contexts in conversation. Psychology of Learning and Motivation, 62, 59-99. doi https://doi.org/10.1016/bs.plm.2014.09.003

Brunner, L. (1979). Smiles can be back channels. Journal of Personality and Social Psychology, 37, $728-734$.

Carlomagno, S., Pandolfi, M., Marini, A., Diiasi, G., \& Cristilli, C. (2005). Coverbal gestures in alzheimer's type dementia. Cortex, 41, 535-546. doi 10.1016/s0010-9452(08)70193-x

Carlomagno, S., Zulian, N., Razzano, C., De Mercurio, I., \& Marini, A. (2013). Coverbal gestures in the recovery from severe fluent aphasia: a pilot study. J Commun Disord, 46, 84-99. doi $10.1016 / \mathrm{j} \cdot \mathrm{j}$ comdis.2012.08.007

Caute, A., Pring, T., Cocks, N., Cruice, M., Best, W., \& Marshall, J. (2013). Enhancing communication through gesture and naming therapy. Journal of Speech, Language ES Hearing Research, 56, 337-351. doi $0.1044 / 1092-4388(2012 / 11-0232)$

Chafe, W. (1994). Discourse, consciousness, and time.. Chicago: Chicago University Press.

Chambers, C., Tanenhaus, M., Eberhard, K., Filip, H., \& Carlson, G. (2002). Circumscribing referential domains

q during real-time language comprehension. Journal of Memory and Language, 47, 30-49. doi 10.1006/jmla.2001. 2832. 
Chiou, H. S., \& Kennedy, M. R. T. (2009). Switching in adults with aphasia. Aphasiology, 23, 1065-1075.

Cho-Reyes, S., Mack, J., \& Thompson, C. (2016). Grammatical encoding and learning in agrammatic aphasia:

口 Evidence from structural priming. Journal of Memory and Language, 91, 202-218. doi https://doi.org/10. $1016 / j \cdot j m l .2016 .02 .004$

Chovil, N. (1991-1992). Discourse-oriented facial displays in conversation. Research on Language and Social Interaction, 25, 163-194.

Chovil, N. (1997). Facing others: A social communicative perspective on facial displays. In J. Russell, J. FernándezDols, \& G. Mandler (Eds.), The Psychology of Facial Expression Studies in Emotion and Social Interaction (pp. 321-333). Cambridge, UK.: Cambridge University Press.

Cicone, M., Wapner, W., Foldi, N., Zurif, E., \& Gardner, H. (1979). The relation between gesture and language in aphasic communication. Brain and Language, 8, 324-349.

Clark, H. (2005). Coordinating with each other in a material world. Discourse Studies, 7, 507-525. doi https: //doi.org/10.1177/1461445605054404

Clark, H. (2018a). On the logic of speaking in situ. URL: http://www.mpi.nl/events/iwlp2018 july 2nd - July 4th.

Clark, H. (2018b). Talk in honor of Rumelhart Prize Winner Michael Tanenhaus. URL: http://www. cognitivesciencesociety.org/conference/cogsci-2018/july 25 - July 28th.

Clark, H., \& Krych, M. (2004). Speaking while monitoring addressees for understanding. Journal of Memory and Language, 50, 62-81. doi $10.1016 / \mathrm{j} \cdot \mathrm{jml} .2003 .08 .004$

Clark, H., \& Wilkes-Gibbs, D. (1986). Referring as a collaborative process. Cognition, 22, 1-39. doi https://doi. org/10.1016/0010-0277(86)90010-7.

Clark, H. H. (1996). Using Language. Cambridge: Cambridge University Press.

Clark, H. H., \& Brennan, S. (1991). Grounding in communication. In L. Resnick, J. Levine, \& S. Teasley (Eds.), Perspectives on Socially Shared Cognition. Washington: American Psychological Association.

Cocks, N., Byrne, S., Pritchard, M., Morgan, G., \& Dipper, L. (2018). Integration of speech and gesture in aphasia. Int J Lang Commun Disord, . doi 10.1111/1460-6984.12372

Cocks, N., Dipper, L., Pritchard, M., \& Morgan, G. (2013). The impact of impaired semantic knowledge on spontaneous iconic gesture production. Aphasiology, 27, 1050-1069. doi 10.1080/02687038.2013.770816

Cocks, N., Sautin, L., Kita, S., Morgan, G., \& Zlotowitz, S. (2009). Gesture and speech integration: an exploratory study of a man with aphasia. Int J Lang Commun Disord, 44, 795-804. doi 10.1080/13682820802256965 
Cole, J. (2015). Prosody in context: a review. Language, Cognition and Neuroscience, 30, 1-31. doi 10.1080/ 23273798.2014 .963130

Cornelissen, K., Laine, M., Tarkiainen, A., Järvensivu, T., Martin, N., \& Salmelin, R. (2003). Adult brain plasticity elicited by anomia treatment. Journal of Cognitive Neuroscience, 15, 444-461. doi 10.1162/089892903321593153

Crespo Sendra, V., Kaland, C., Swerts, M., \& Prieto, P. (2013). Perceiving incredulity: The role of intonation and facial gestures. Journal of Pragmatics, 47, 1-13. doi $10.1016 / \mathrm{j}$.pragma.2012.08.008

Cruice, M., Johansson, M. B., Isaksen, J., \& Horton, S. (2018). Reporting interventions in communication partner

\ training: a critical review and narrative synthesis of the literature. Aphasiology, (pp. 1-32). doi 10.1080/02687038. 2018.1482406

Cunningham, R., Farrow, V., Davies, C., \& Lincoln, N. (1995). Reliability of the assessment of communicative effectiveness in severe aphasia. Eur J Disord Commun, 30, 1-16.

Cutler, A., Dahan, D., \& van Donselaar, W. (1997). Prosody in the comprehension of spoken language: A literature review. Language and Speech, 40, 141-201.

Damico, J. S., Oelschlaeger, M., \& Simmons-Mackie, N. (1999). Qualitative methods in aphasia research: conversation analysis. Aphasiology, 13, 667-679.

Daniloff, J. K., Fritelli, G., Buckingham, H., Hoffman, P., \& Daniloff, R. (1986). Amer-ind versus asl: Recognition and imitation in aphasic subjects. Brain and Language, 28, 95-113.

Danly, M., Cooper, W., \& Shapiro, B. (1983). Fundamental frequency, language processing, and linguistic structure in wernicke's aphasia. Brain and Language, 19, 1-24.

Danly, M., \& Shapiro, B. (1982). Speech prosody in broca's aphasia. Brain and Language, 16, 171-190.

Daumüller, M., \& Goldenberg, G. (2010). Therapy to improve gestural expression in aphasia: a controlled clinical trial. Clinical Rehabilitation, 24, 55-65. doi 10.1177/0269215509343327

Davidson, B., \& Worrall, L. (2000). The assessment of activity limitation in functional communication: Challenges and choices. In L. Worrall, \& C. Frattali (Eds.), Neurogenic Communication Disorders: a Functional Approach. New York: Thieme Medical Publishers.

Davidson, B., Worrall, L., \& Hickson, L. (2003). Identifying the communication activities of older people with aphasia: Evidence from naturalistic observation. Aphasiology, 17, 243-264. doi 10.1080/02687030244000653

Davidson, B., Worrall, L., \& Hickson, L. (2008). Exploring the interactional dimension of social communication: A collective case study of older people with aphasia. Aphasiology, 22, 235-257. doi 10.1080/02687030701268024

Diamond, A. (2013). Executive functions. Annual Review of Psychology, 64, 135-168. doi 10.1146/ annurev-psych-113011-143750 
Dickey, M. W., Warren, T., Milburn, E. A., Hayes, R. A., \& Lei, C.-M. (2014). Verb-based anticipatory processing in aphasia. Frontiers in Psychology, . doi 10.3389/conf.fpsyg.2015.65.00068

Dietz, A., Hux, K., McKelvey, M., Beukelman, D., \& Weissling, K. (2009). Reading comprehension by people with chronic aphasia: A comparison of three levels of visuographic contextual support. Aphasiology, 23, 1053-1064. doi $10.1080 / 02687030802635832$.

Dietz, A., Knollman-Porter, K., \& Hux, K. (2013). Supported reading comprehension for people with aphasia: Photographic and linguistic supports. 43rd Clinical Aphasiology Conference Tucson, AZ: Clinical Aphasiology Paper.

Dijkstra, C., Krahmer, E., \& Swerts, M. (2013). Manipulating uncertainty: the contribution of different audiovisual prosodic cues to the perception of confidence. In Speech Prosody 2006 Conference.

Dipper, L., Pritchard, M., Morgan, G., \& Cocks, N. (2015). The language-gesture connection: Evidence from aphasia. Clin Linguist Phon, 29, 748-63. doi 10.3109/02699206.2015.1036462

Dogil, G., Hildebrandt, G., \& Schürmeier, K. (1990). The communicative function of prosody in a semantic jargon aphasia. Journal of Neurolinguistics, 5, 353-369. doi 10.1016/0911-6044(90)90019-u

Doyle, P., Hula, W., Hula, S., Ross, K., Wambaugh, J., Schumacher, J., \& Roehrig, A. (2012). The aphasia communication outcome measure: Item reduction, scaling, and concurrent validity of self-reported communicative functioning in aphasia. Clinical Aphasiology Paper, .

Eberhard, K., Spivey-Knowlton, M., Sedivy, J., \& Tanenhaus, M. (1995). Eye movements as a window into realtime spoken language comprehension in natural contexts. Journal of Psycholinguistic Research, 24, 409-436. doi https://doi.org/10.1007/BF02143160

Eggenberger, N., Preisig, B. C., Schumacher, R., Hopfner, S., Vanbellingen, T., Nyffeler, T., Gutbrod, K., Annoni, J. M., Bohlhalter, S., Cazzoli, D., \& Muri, R. M. (2016). Comprehension of co-speech gestures in aphasic patients: An eye movement study. PLoS One, 11, e0146583. doi 10.1371/journal.pone.0146583

van Egmond, M., van Ewijk, L., \& Avrutin, S. (2015). Zipf's law in non-fluent aphasia. Journal of Quantitative Linguistics, 22, 233-249. doi 10.1080/09296174.2015.1037158

Eimer, M. (2014). The neural basis of attentional control in visual search. Trends in Cognitive Sciences, 18, 526-535. doi $10.1016 /$ j.tics.2014.05.005

Ekman, P. (1979). About brows: emotional and conversational signals. In M. von Cranach, K. Foppa, W. Lepenies, \& D. Ploog (Eds.), Human ethology (p. 169-248). Cambridge: Cambridge University Press.

Ekman, P. (1997). Should we call it expression or communication? Innovation, 10, 333-344.

Elman, R. J., \& Bernstein-Ellis, E. (1995). What is functional? American Journal of Speech-Language Pathology, 4, 115-117. 
Emery, N. (2000). The eyes have it: the neuroethology, function and evolution of social gaze. Neuroscience and Biobehavioral Reviews, 24, 581-604. doi https://doi.org/10.1016/S0149-7634(00)00025-7

Eriksson, K., Hartelius, L., \& Saldert, C. (2016). Participant characteristics and observed support in conversations

Evans, G., Lambon Ralph, M., \& Woollams, A. (2012). What's in a word? a parametric study of semantic influences on visual word recognition. Psychonomic Bulletin \& Review, 19, 325-331. doi 10.3758/s13423-011-0213-7

van Ewijk, L., \& Avrutin, S. (2016). Lexical access in non-fluent aphasia: a bit more on reduced processing. Aphasiology, 30, 1264-1282. doi 10.1080/02687038.2015.1135867.

Ferguson, A. (1994). The influence of aphasia, familiarity and activity on conversational repair. Aphasiology, 8, 143-157. doi Doi10.1080/02687039408248647

Ferguson, A. (1998). Conversational turn-taking and repair in fluent aphasia. Aphasiology, 12, 1007-1031. doi 10. $1080 / 02687039808249466$

Ferro, J. M., Santos, M. E., Castro-caldas, A., \& Mariano, M. G. (1980). Gesture recognition in aphasia. Journal of Clinical Neuropsychology, 2, 277-292. doi $10.1080 / 01688638008403800$

Flecha-García, M. L. (2010). Eyebrow raises in dialogue and their relation to discourse structure, utterance function and pitch accents in english. Speech Communication, 52, 542-554. doi $10.1016 / \mathrm{j}$.specom.2009.12.003

Ford, C., \& Thompson, S. (1996). Interaction and grammar. chapter Interactional units in conversation: Syntactic, intonational, and pragmatic resources for the projection of turn completion. (pp. 135-184). Cambridge, UK: Cambridge University Press.

Frankel, T., Penn, C., \& Ormond-Brown, D. (2007). Executive dysfunction as an explanatory basis for conversation symptoms of aphasia: A pilot study. Aphasiology, 21, 814-828. doi 10.1080/02687030701192448

Frattali, C., Thompson, C., Holland, A., Wohl, C., \& Ferketic, M. (1995). Functional Assessment of Communication Skills for Adults (ASHA-FACS). Rockville, MD: American Speech-Language Hearing Association.

Frith, C. (2009). Role of facial expressions in social interactions. Philos Trans R Soc Lond B Biol Sci, 364, 3453-8. doi $10.1098 /$ rstb.2009.0142.

Fucetola, R., Connor, L. T., Perry, J., Leo, P., Tucker, F. M., \& Corbetta, M. (2006). Aphasia severity, semantics,

1. and depression predict functional communication in acquired aphasia. Aphasiology, 20, 449-461. doi 10.1080/ 1550 02687030500390177 .

Fussell, S., \& Krauss, R. (1992). Coordination of knowledge in communication: Effects of speakers' assumptions about what others know. Journal of Personality and Social Psychology, 62, 378-391. doi 10.1037/0022-3514.62.3.378 
Garrett, K., \& Huth, C. (2002). The impact of graphic contextual information and instruction on the conversational behaviours of a person with severe aphasia. Aphasiology, 16, 523-536. doi 10.1080/02687030244000149

Garrod, S., \& Anderson, A. (1987). Saying what you mean in dialogue: A study in conceptual and semantic co-ordination. Cognition, 27, 181-218. doi https://doi.org/10.1016/0010-0277(87)90018-7

Geigenberger, A., \& Ziegler, W. (2001). Receptive prosodic processing in aphasia. Aphasiology, 15, 1169-1187. doi $10.1080 / 02687040143000555$.

Gerwing, J., \& Bavelas, J. (2004). Linguistic influences on gesture's form. Gesture, 4, 157-195. doi http://dx.doi. 1560 org/10.1075/gest.4.2.04ger

Gianotti, G., \& Lemmo, M. (1976). Comprehension of symbolic gestures in aphasia. Brain and Language, 3, 451-460.

Gilabert, R. (2007). Effects of manipulating task complexity on self-repairs during 12 oral production. International Review of Applied Linguistics in Language Teaching, 45, 215-240. doi 10.1515/iral.2007.010

Givón, T. (1983). Topic continuity in discourse: a quantitative cross-language study. chapter Topic continuity in 1565

Glueckauf, R. L., Blonder, L. X., Ecklund-Johnson, E., Maher, L., Crosson, B., \& Gonzalez-Rothi, L. (2003). Functional outcome questionnaire for aphasia: overview and preliminary psychometric evaluation. NeuroRehabilitation, $18,281-90$.

Goodglass, H., \& Kaplan, E. (1972). The assessment of aphasia and related disorders. Philadelphia: Lea \& Febiger.

Goodwin, C. (1981). Conversational Organization: Interaction between Speakers and Hearers. Language, Thought and Culture: Advances in the Study of Cognition. New York: Academic Press.

Goodwin, C. (1995). Co-constructing meaning in conversations with an aphasic man. Research on Language and Social Interaction, 28, 233-260.

Goodwin, C. (2000). Language and gesture. Language Culture and Cognition book section Gesture, aphasia, and interaction. (pp. 84-98). Cambridge: Cambridge University Press.

Green, G. (1982). Assessment and treatment of the adult with severe aphasia: Aiming for functional generalisation. Australian Journal of Human Communication Disorders, 10, 11-23. doi 10.3109/asl2.1982.10.issue-1.02

Gundel, J., Hedberg, N., \& Zacharski, R. (1993). Cognitive status and the form of referring expressions in discourse. Language, 69, 274-307. doi $10.2307 / 416535$

Hachioui, H. E., Visch-Brink, E. G., Lingsma, H. F., van de Sandt-Koenderman, M. W. M. E., Dippel, D. W. J., Koudstaal, P. J., \& Middelkoop, H. A. M. (2014). Nonlinguistic cognitive impairment in poststroke aphasia. Neurorehabilitation and Neural Repair, 28, 273-281. doi 10.1177/1545968313508467 
Hagoort, P., Brown, C. M., \& Swaab, T. Y. (1996). Lexical-semantic event-related potential effects in patients with left hemisphere lesions and aphasia, and patients with right hemisphere lesions without aphasia. Brain, 119, 627-649. doi 10.1093/brain/119.2.627

Hanna, J., \& Brennan, S. (2007). Speakers' eye gaze disambiguates referring expressions early during face-to-face conversation. Journal of Memory and Language, 57, 596-615. doi 10.1016/j·jml.2007.01.008

Hanna, J., Tanenhaus, M., \& Trueswell, J. (2003). The effects of common ground and perspective on domains

of referential interpretation. Journal of Memory and Language, 49, 43-61. doi https://doi.org/10.1016/ S0749-596X(03)00022-6

Hanne, S., Burchert, F., Bleser, R. D., \& Vasishth, S. (2015a). Sentence comprehension and morphological cues in aphasia: What eye-tracking reveals about integration and prediction. Journal of Neurolinguistics, 34, 83-111. doi $10.1016 / j \cdot$ jneuroling.2014.12.003.

Hanne, S., Burchert, F., \& Vasishth, S. (2015b). On the nature of the subject-object asymmetry in wh-question

口 comprehension in aphasia: evidence from eye tracking. Aphasiology, 30, 435-462. doi 10.1080/02687038.2015. 1065469

Hartsuiker, R., \& Kolk, H. (1998). Syntactic facilitation in agrammatic sentence production. Brain and Language, 62, 221-254. doi https://doi.org/10.1006/brln.1997.1905

Hartsuiker, R. J., \& Kolk, H. H. (2001). Error monitoring in speech production: A computational test of the perceptual loop theory. Cognitive Psychology, 42, 113-157. doi 10.1006/cogp.2000.0744.

Hasson, U., Egidi, G., Marelli, M., \& Willems, R. M. (2018). Grounding the neurobiology of language in first principles: The necessity of non-language-centric explanations for language comprehension. Cognition, 180, 135157. doi 10.1016/j.cognition.2018.06.018

Hellbernd, N., \& Sammler, D. (2016). Prosody conveys speaker's intentions: Acoustic cues for speech act perception. Journal of Memory and Language, 88, 70-86. doi 10.1016/j.jml.2016.01.001.

Heller, D., Gorman, K. S., \& Tanenhaus, M. K. (2012). To name or to describe: shared knowledge affects referential form. Top Cogn Sci, 4, 290-305. doi 10.1111/j.1756-8765.2012.01182.x

Helm-Estabrooks, N. (2002). Cognition and aphasia: a discussion and a study. Journal of Communication Disorders, 35, 171-186. doi 10.1016/s0021-9924(02)00063-1

Hengst, J. (2003). Collaborative referencing between individuals with aphasia and routine communication partners. Journal of Speech Language and Hearing Research, 46, 831-848. doi 10.1044/1092-4388(2003/065)

Hengst, J., Frame, S., Neuman-Stritzel, T., \& Gannaway, R. (2005). Using others' words: Conversational use of reported speech by individuals with aphasia and their communication partners. Journal of Speech, Language, and Hearing Research, . 
Hermann, M., Koch, U., Johannsen-Horbach, H., \& Wallesch, C. (1989). Communicative skills in chronic and severe nonfluent aphasia. Brain and Language, 31, 339-352.

Hermann, M., Reichle, T., Lucius-Hoene, G., Wallesch, C., \& Johannsen-Horbach, H. (1988). Nonverbal communication as a compensative strategy for severely nonfluent aphasics?-a quantitative approach. Brain and Language, $33,41-54$.

Heuer, S., \& Hallowell, B. (2015). A novel eye-tracking method to assess attention allocation in individuals with and without aphasia using a dual-task paradigm. Journal of Communication Disorders, 55, 15-30. doi 10.1016/j. jcomdis.2015.01.005

Hirschberg, J. (2002). Communication and prosody: Functional aspects of prosody. Speech Communication, 36, 1625 $31-43$.

Ho, K., Weiss, S., Garrett, K., \& Lloyd, L. (2005). The effect of remnant and pictographic books on the communicative interaction of individuals with global aphasia. Augmentative and Alternative Communication, 21, 218-232. doi $10.1080 / 07434610400016694$.

Hogrefe, K., Ziegler, W., Weidinger, N., \& Goldenberg, G. (2012). Non-verbal communication in severe aphasia: influence of aphasia, apraxia, or semantic processing? Cortex, 48, 952-62. doi 10.1016/j.cortex.2011.02.022

Hogrefe, K., Ziegler, W., Wiesmayer, S., Weidinger, N., \& Goldenberg, G. (2013). The actual and potential use of gestures for communication in aphasia. Aphasiology, 27, 1070-1089. doi 10.1080/02687038.2013.803515

Holland, A. (1982). Observing functional communication of aphasic adults. Journal of Speech and Hearing Disorders, $47,50-56$.

Holland, A., Frattali, C., \& Fromm, D. (1999). CADL-2 : communication activities of daily living. Austin, Texas: Pro-ed.

Holland, A., \& Thompson, C. (1998). Outcomes measurement: Definitions, dimensions and perspectives. In C. Frattali (Ed.), Measuring outcomes in speech-language pathology book section Functional outcome measurement in Aphasia. (p. 245-266). New York: Thieme.

Holler, J., Kendrick, K. H., \& Levinson, S. C. (2017). Processing language in face-to-face conversation: Questions with gestures get faster responses. Psychon Bull Rev, . doi 10.3758/s13423-017-1363-z

Holler, J., Shovelton, H., \& Beattie, G. (2009). Do iconic hand gestures really contribute to the communication 口 of semantic information in a face-to-face context? Journal of Nonverbal Behavior, 33, 73-88. doi 10.1007/ s10919-008-0063-9

Holler, J., \& Stevens, R. (2007). The effect of common ground on how speakers use gesture and speech to rep-

口 resent size information. Journal of Language and Social Psychology, 26, 4-27. doi https://doi.org/10.1177/ $0261927 \times 06296428$ 
Holler, J., \& Wilkin, K. (2009). Communicating common ground: How mutually shared knowledge influences speech and gesture in a narrative task. Language and Cognitive Processes, 24, 267-289. doi 10.1080/01690960802095545

Horton, S. (2008). Learning-in-interaction: Resourceful work by people with aphasia and therapists in the course of language impairment therapy. Aphasiology, 22, 985-1014. doi 10.1080/02687030802066582

Horton, W., \& Gerrig, R. (2005). The impact of memory demands on audience design during language production. Cognition, 96, 127-42. doi 10.1016/j.cognition.2004.07.001.

¡Hostetter, A. B. (2011). When do gestures communicate? a meta-analysis. Psychol Bull, 137, 297-315. doi 10. $1037 / \mathrm{a} 0022128$

Howard, D., Swinburn, K., \& Porter, G. (2004). Comprehensive Aphasia Test. Routledge. Psychology Press.

Howe, T., Worrall, L., \& Louise Hickson, L. (2008). Observing people with aphasia: Environmental factors that influence their community participation. Aphasiology, 22, 618-643. doi 10.1080/02687030701536024

Huettig, F., \& Hartsuiker, R. J. (2010). Listening to yourself is like listening to others: External, but not internal, $1080 / 01690960903046926$

Huettig, F., Rommers, J., \& Meyer, A. (2011). Using the visual world paradigm to study language processing: A review and critical evaluation. Acta Psychologica, 137, 151-171. doi 10.1016/j.actpsy.2010.11.003.

Hula, W., \& McNeil, M. (2008). Models of Attention and Dual-Task Performance as Explanatory Constructs in Aphasia. Seminars in Speech and Language, 29, 169-187. doi 10.1055/s-0028-1082882.

Hux, K., Buechter, M., Wallace, S., \& Weissling, K. (2010). Using visual scene displays to create a shared communication space for a person with aphasia. Aphasiology, 24, 643-660. doi 10.1080/02687030902869299

Irwin, B. (2012). Patient-Reported Outcome Measures in Aphasia. Perspectives on Neurophysiology and Neurogenic Speech and Language Disorders, 22, 160. doi 10.1044/nnsld22.4.160

Irwin, W. H., Wertz, R. T., \& Avent, J. R. (2002). Relationships among language impairment, functional communication, and pragmatic performance in aphasia. Aphasiology, 16, 823-835. doi 10.1080/02687030244000086

Isaacs, E., \& Clark, H. (1987). References in conversation between experts and novices. Journal of Experimental Psychology: General, 116, 26-37. doi 10.1037/0096-3445.116.1.26

Ishikawa, T. (2007). Investigating tasks in formal language learning. chapter The effect of increasing task complexity along the [Here-and-Now] dimension on L2 written narrative discourse. (pp. 136-156). Clevedon, UK: Multilingual Matters.

Itier, R. J., \& Batty, M. (2009). Neural bases of eye and gaze processing: the core of social cognition. Neurosci Biobehav Rev, 33, 843-63. doi 10.1016/j.neubiorev.2009.02.004 
¿Iiang, X., \& Pell, M. D. (2017). The sound of confidence and doubt. Speech Communication, 88, 106-126. doi 10. $1680 \quad 1016 / \mathrm{j} \cdot$.specom.2017.01.011

Jordan, T., \& Sergeant, P. (2000). Effects of distance on visual and audiovisual speech recognition. Language and Speech, 43, 107-124. doi https://doi.org/10.1177/00238309000430010401.

Just, M. A., \& Carpenter, P. A. (1992). A capacity theory of comprehension: Individual differences in working memory. Psychological Review, 99, 122-149. doi 10.1037/0033-295x.99.1.122

Kagan, A., Black, S. E., Felson Duchan, J., Simmons-Mackie, N., \& Square, P. (2001). Training volunteers as conversation partners using "supported conversation for adults with aphasia" (sca): A controlled trial. Journal of Speech, Language and Hearing Research, 44, 624.

Kahneman, D. (1973). Attention and effort. Englewood Cliffs, NJ: Prentice-Hall.

Kasselimis, D. S., Simos, P. G., Peppas, C., Evdokimidis, I., \& Potagas, C. (2017). The unbridged gap between clinical diagnosis and contemporary research on aphasia: A short discussion on the validity and clinical utility of taxonomic categories. Brain and Language, 164, 63-67. doi 10.1016/j.bandl.2016.10.005

Kaukomaa, T., Peräkylä, A., \& Ruusuvuoric, J. (2014). Foreshadowing a problem: Turn-opening frowns in conversation. Journal of Pragmatics, 71, 132-147. doi https://doi.org/10.1016/j.pragma.2014.08.002

Kelly, S., Healey, M., Özyürek, A., \& Holler, J. (2015). The processing of speech, gesture, and action during language comprehension. Psychon Bull Rev, 22, 517-23. doi 10.3758/s13423-014-0681-7.

Kelly, S., Özyürek, A., \& Maris, E. (2010). Two sides of the same coin: Speech and gesture mutually interact to enhance comprehension. Psychological Science, 21, 260-267.

Kendon, A. (1967). Some functions of gaze-direction in social interaction. Acta Psychologica, 26, 22-63.

Kendon, A. (1980). Gesticulation and speech: Two aspects of the process of utterance. In M. R. Key (Ed.), The relationship of verbal and nonverbal communication (pp. 207-227). The Hague, the Netherlands: Mouton Publishers.

Kendon, A. (1994). Do gestures communicate? a review. Research on Language \& Social Interaction, 27, 175-200. doi $10.1207 /$ s15327973rlsi2703_2

Kendon, A. (2004). Gesture. Visible Action as Utterance. Cambridge, UK: Cambridge University Press.

Kendrick, K. H., \& Drew, P. (2016). Recruitment: Offers, requests, and the organization of assistance in interaction. Research on Language and Social Interaction, 49, 1-19. doi 10.1080/08351813.2016.1126436

Khachatryan, E., De Letter, M., Vanhoof, G., Goeleven, A., \& Van Hulle, M. M. (2017). Sentence context prevails over word association in aphasia patients with spared comprehension: Evidence from n400 event-related potential. Frontiers in Human Neuroscience, 10, 684. doi 10.3389/fnhum.2016.00684 
Knoeferle, P., \& Guerra, E. (2016). Visually situated language comprehension. Language and Linguistics Compass, 10, 66-82. doi https://doi.org/10.1111/lnc3.12177.

Kolk, H., \& Heeschen, C. (1992). Agrammatism, paragrammatism and the management of language. Language and Cognitive Processes, 7, 89-129. doi/https://doi.org/10.1080/01690969208409381

Kutas, M., \& Federmeier, K. D. (2011). Thirty years and counting: finding meaning in the n400 component of the event-related brain potential (erp). Annu Rev Psychol, 62, 621-47. doi 10.1146/annurev.psych.093008.131123

Laakso, M. (2014a). Aphasia sufferers' displays of affect in conversation. Research on Language and Social Interaction, 47, 404-425. doi $10.1080 / 08351813.2014 .958280$

Laakso, M. (2014b). Collaborative participation in aphasic word searching: comparison between significant others and speech and language therapists. Aphasiology, 29, 269-290. doi $10.1080 / 02687038.2013 .878450$

Laakso, M., \& Godt, S. (2016). Recipient participation in conversations involving participants with fluent or nonfluent aphasia. Clinical Linguistics \& Phonetics, 30, 770-789. doi 10.1080/02699206.2016.1221997

Ladd, D. (1996). Intonational Phonology. Cambridge: Cambridge University Press.

Lee, J., \& Man, G. (2017). Language recovery in aphasia following implicit structural priming training: a case study. Aphasiology, 31, 1441-1458. doi/https://doi.org/10.1080/02687038.2017.1306638

Lesser, R., \& Algar, L. (1995). Towards combining the cognitive neuropsychological and the pragmatic in aphasia therapy. Neuropsychological Rehabilitation, 5, 67-92. doi Doi10.1080/09602019508520176

Levelt, W. (1992). The perceptual loop theory not disconfirmed: A reply to MacKay. Consciousness and Cognition, 1, 226-230. doi 10.1016/1053-8100(92)90062-f

Levelt, W. J. M. (1989). Speaking. From intention to articulation.. Cambridge, MA: MIT Press.

Levelt, W. J. M., Roelofs, A., \& Meyer, A. S. (1999). A theory of lexical access in speech production. Behavioral and Brain Sciences, 22. doi $10.1017 / \mathrm{s} 0140525 \times 99001776$

Lind, M. (2007). Prosodic contextualization of minimal responses to yes/no-questions in aphasic talk-in-interaction:

口 a descriptive single-case study of a norwegian aphasic speaker. Logoped Phoniatr Vocol, 32, 9-16. doi 10.1080/ 14015430600630860

Lindsay, J., \& Wilkinson, R. (1999). Repair sequences in aphasic talk: a comparison of aphasic-speech and language therapist and aphasic-spouse conversations. Aphasiology, 13, 305-325. doi 10.1080/026870399402118.

Linebaugh, C., Kryzer, K., Oden, S., \& Myers, P. (2006). Reapportionment of communicative burden in aphasia: A study of narrative interaction. Aphasiology, 20, 84-96. doi 10.1080/02687030500369452.

Linnik, A., Bastiaanse, R., \& Hohle, B. (2016). Discourse production in aphasia: a current review of theoretical and methodological challenges. Aphasiology, 30, 765-800. doi 10.1080/02687038.2015.1113489 
Lock, S., Wilkinson, R., Bryan, K., Maxim, J., Edmundson, A., Bruce, C., \& Moir, D. (2001). Supporting partners of people with aphasia in relationships and conversation (spparc). International Journal of Language \& Communication Disorders, 36, 25-30. doi 10.3109/13682820109177853. arXiv:https://www.tandfonline.com/doi/pdf/10.3109/13682820109177853

Luria, A. R. (1970). Traumatic aphasia: Its syndromes, psychology, and treatment.. New York: Mouton.

Lysander, K., \& Horton, W. (2012). Conversational grounding in younger and older adults: The effect of partner vis-

घ ibility and referent abstractness in task-oriented dialogue. Discourse Processes, 49, 29-60. doi 10.1080/0163853x.

Lomas, J., Pickard, L., Bester, S., Elbard, H., Finlayson, A., \& Zoghaib, C. (1989). The communicative effectiveness index: development and psychometric evaluation of a functional communication measure for adult aphasia. $J$ Speech Hear Disord, 54, 113-24.

Long, A., Hesketh, A., \& Bowen, A. (2009). Communication outcome after stroke: a new measure of the carer's perspective. Clin Rehabil, 23, 846-56. doi 10.1177/0269215509336055

Long, A., Hesketh, A., Paszek, G., Booth, M., \& Bowen, A. (2008). Development of a reliable self-report outcome measure for pragmatic trials of communication therapy following stroke: the communication outcome after stroke (coast) scale. Clin Rehabil, 22, 1083-94. doi 10.1177/0269215508090091

Love, R., \& Webb, W. (1977). The efficacy of cueing techniques in broca's aphasia. Journal of Speech and Hearing Disorders, 42, 170. doi 10.1044/jshd.4202.170

Luck, S. (1994). Cognitive and neural mechanisms of visual search. Current Opinion in Neurobiology, 4, $183-188$. doi $10.1016 / 0959-4388(94) 90070-1$

2011.625547

MacDonald, M., Pearlmutter, N., \& Seidenberg, M. (1994). The lexical nature of syntactic ambiguity resolution. Psychological Review, 101, 676-703. doi http://dx.doi.org/10.1037/0033-295X.101.4.676

Mack, J. E., Nerantzini, M., \& Thompson, C. (2017). Recovery of sentence production processes following language

1. treatment in aphasia: Evidence from eyetracking. Frontiers in Human Neuroscience, 11, 1-20. doi https://doi. 1765 org/10.3389/fnhum.2017.00101.

Mahowald, K., James, A., Futrell, R., \& Gibson, E. (2016). A meta-analysis of syntactic priming in language production. Journal of Memory and Language, 91, 5-27. doi/https://doi.org/10.1016/j.jml.2016.03.009

Manochiopinig, S., Sheard, C., \& Reed, V. A. (1992). Pragmatic assessment in adult aphasia - a clinical review. Aphasiology, 6, 519-533. doi Doi10.1080/02687039208249489

1770 Marshall, J. (2006). Jargon aphasia: What have we learned? Aphasiology, 20, 387-410. doi 10.1080/ 02687030500489946 
Marshall, J., Best, W., Cocks, N., Cruice, M., Pring, T., Bulcock, G., Creek, G., Eales, N., Lockhart Mummery, A., Matthews, N., \& Caute, A. (2012). Gesture and naming therapy for people with severe aphasia: A group study. Journal of Speech, Language \& Hearing Research, 55, 726-738. doi 10.1044/1092-4388(2011/11-0219)

Marshall, J., Robson, J., Pring, T., \& Chiat, S. (1998). Why does monitoring fail in jargon aphasia? comprehension, judgment, and therapy evidence. Brain and Language, 63, 79-107. doi 10.1006/brln.1997.1936

Marshall, J., Roper, A., Galliers, J., Wilson, S., Cocks, N., Muscroft, S., \& Pring, T. (2013). Computer delivery of gesture therapy for people with severe aphasia. Aphasiology, 27, 1128-1146. doi 10.1080/02687038.2013.786803

Martin, N., Fink, R., \& Laine, M. (2004). Treatment of word retrieval deficits with contextual priming. Aphasiology, 18, 457-471. doi 10.1080/02687030444000129.

Martin, N., \& Laine, M. (2000). Effects of contextual priming on impaired word retrieval. Aphasiology, 14, 53-70. doi:https://doi.org/10.1080/026870300401595

Matthews, D., Lieven, E., Theakston, A., \& Tomasello, M. (2006). The effect of perceptual availability and prior

1 discourse on young children's use of referring expressions. Applied Psycholinguistics, 27, 403-422. doi 10.1017. S0142716406060334.

McCarthy, L., Kalinyak-Fliszar, M., Kohen, F., \& Martin, N. (2017). Effects of semantic context on access to words of low imageability in deep-phonological dysphasia: a treatment case study. Aphasiology, 31, 542-562. doi:https://doi.org/10.1080/02687038.2016.1208803

McDermott, R., \& Tylbor, H. (1983). On the necessity of collusion in conversation. Text - Interdisciplinary Journal for the Study of Discourse, 3. doi https://doi.org/10.1515/text.1.1983.3.3.277

McGurk, H., \& MacDonald, J. (1976). Hearing lips and seeing voices. Nature, 264, 746-748. doi 10.1038/264746a0

McNeil, M. R., Doyle, P. J., Fossett, T. R. D., Park, G. H., \& Goda, A. J. (2001). Reliability and concurrent validity of the information unit scoring metric for the story retelling procedure. Aphasiology, 15, 991-1006. doi $10.1080 / 02687040143000348$.

McNeil, M. R., Odell, K., \& Tseng, C.-H. (1991). Toward the integration of resource allocation into a general theory of aphasia. Clinical Aphasiology, .

McNeill, D. (1992). Hand and Mind: What Gestures Reveal about Thought. Chicago and London: The University of Chicago Press.

Meisel, J. (1987). First and second language acquisition processes. chapter Reference to past events and actions in the development of natural second language acquisition. (pp. 206-224). Cambridge, MA.: Newbury House.

Meteyard, L., \& Vigliocco, G. (in press). Oxford handbook of psycholinguistics. chapter Lexico-semantics. Oxford University Press. 
Metzing, C., \& Brennan, S. (2003). When conceptual pacts are broken: Partner-specific effects on the comprehension of referring expressions. Journal of Memory and Language, 49, 201-213. doi 10.1016/s0749-596x(03)00028-7

Nicholas, M., Sinotte, M. P., \& Helm-Estabrooks, N. (2005). Using a computer to communicate: Effect of executive function impairments in people with severe aphasia. Aphasiology, 19, 1052-1065. doi 10.1080/02687030544000245

Nicholas, M., Sinotte, M. P., \& Helm-Estabrooks, N. (2011). C-speak aphasia alternative communication program for people with severe aphasia: importance of executive functioning and semantic knowledge. Neuropsychol Rehabil,

Nickels, L., \& Howard, D. (1995). Phonological errors in aphasic naming: Comprehension, monitoring and lexicality. Cortex, 31, 209-237. doi $10.1016 /$ s0010-9452(13)80360-7

van Nispen, K., van de Sandt-Koenderman, M., Mol, L., \& Krahmer, E. (2016). Pantomime production by people with aphasia: What are influencing factors? J Speech Lang Hear Res, 59, 745-58. doi 10.1044/2015_JSLHR-L-15-0166 
van Nispen, K., van de Sandt-Koenderman, M., Sekine, K., Krahmer, E., \& Rose, M. (2017). Part of the message comes in gesture: how people with aphasia convey information in different gesture types as compared with information in their speech. Aphasiology, 31, 1078-1103. doi 10.1080/02687038.2017.1301368

Norrick, N. R. (2010). Incorporating listener evaluation into stories. Narrative Inquiry, 20, 183-204.

Nozari, N., Dell, G. S., \& Schwartz, M. F. (2011). Is comprehension necessary for error detection? a conflict-based

Nykanen, A., Nyrkko, H., Nykanen, M., Brunou, R., \& Rautakoski, P. (2013). Communication therapy for people with aphasia and their partners (appute). Aphasiology, 27, 1159-1179. doi 10.1080/02687038.2013.802284

Oelschlaeger, M., \& Damico, J. (1998). Joint productions as a conversational strategy in aphasia. Clin Linguist Phon, 12, 459-80. doi 10.3109/02699209808985238

Oelschlaeger, M. L., \& Thorne, J. C. (1999). Application of the correct information unit analysis to the naturally occurring conversation of a person with aphasia. J Speech Lang Hear Res, 42, 636-48.

Oomen, C. C., Postma, A., \& Kolk, H. H. (2001). Prearticulatory and Postarticulatory Self-Monitoring in Broca's Aphasia. Cortex, 37, 627-641. doi 10.1016/s0010-9452(08)70610-5

Organization, W. H. (1980). International Classification of Impairments, Disabilities, and Handicaps.

Organization, W. H. (2001). International classification of functioning, disability and health (ICF). Geneva: World Health Organization.

Paivio, A. (1986). Mental representations: A dual coding approach. Oxford, UK: Oxford University Press.

Paivio, A. (1991). Dual coding theory: Retrospect and current status. Canadian Journal of Psychology/Revue Canadienne de Psychologie, 45, 255-287. doi http://dx.doi.org/10.1037/h0084295

Parkinson, B. (2005). Do facial movements express emotions or communicate motives? Personality and Social Psychology Review, 9, 278-311.

Patterson, J., \& Chapey, R. (2008). Assessment of Language Disorders in Adults. (5th ed.). Baltimore, Maryland: Lippincott Williams \& Wilkins.

Pell, M. (1998). Recognition of prosody following unilateral brain lesion: influence of functional and structural

1. attributes of prosodic contours. Neuropsychologia, 36, 701-715. doi/https://doi.org/10.1016/S0028-3932(98) 00008-6

Pell, M., \& Baum, S. (1997). The ability to perceive and comprehend intonation in linguistic and affective contexts by brain-damaged adults. Brain and Language, 57, 80-99. 
Perkins, J., Baran, J., $\&$ ology, 10, 343-362.

Perkins, L. (1995). Applying conversation analysis to aphasia: clinical implications and analytic issues. European Journal of Disorders of Communication, 30, 372-383.

Perkins, L., Crisp, J., \& Walshaw, D. (1999). Exploring conversation analysis as an assessment tool for aphasia: the 1870 issue of reliability. Aphasiology, 13, 259-281. doi https://doi.org/10.1080/026870399402091.

Perlman Lorch, M., Borod, J., \& Koff, E. (1998). The role of emotion in the linguistic and pragmatic aspects of aphasic performance. Journal of Neurolinguistics, 11, 103-118.

Pickering, M., \& Garrod, S. (2004). Toward a mechanistic psychology of dialogue. Behavioral and Brain Sciences, 27, 169-226. doi 10.1017/S0140525X04000056.

Ping, R., \& Goldin-Meadow, S. (2008). Hands in the air: Using ungrounded iconic gestures to teach children conservation of quantity. Developmental Psychology, 44, 1277-1287. doi 10.1037/0012-1649.44.5.1277

Postma, A. (1997). Speech production: motor control, brain research and fluency disorders. chapter On the mechanisms of speech monitoring. Amsterdam: Elsevier.

Postma, A. (2000). Detection of errors during speech production: a review of speech monitoring models. Cognition, 77, 97-132. doi $10.1016 / \mathrm{s} 0010-0277(00) 00090-1$

Postma, C. C. E. O. . A. (2002). Limitations in processing resources and speech monitoring. Language and Cognitive Processes, 17, 163-184. doi 10.1080/01690960143000010

Pound, C., Parr, S., Lindsay, J., \& Woolf, C. (2000). Beyond aphasia, therapies for living with communication disability. Routledge.

Preisig, B., Eggenberger, N., Zito, G., Vanbellingen, T., Schumacher, R., Hopfner, S., Gutbrod, K., Nyffeler, T., Cazzoli, D., Annoni, J. M., Bohlhalter, S., \& Müri, R. (2016). Eye gaze behaviour at turn transition: How aphasic patients process speakers' turns during video observation. Journal of Cognitive Neuroscience, 28, $1613-1624$. doi 10.7892 /boris. 83504 .

Preisig, B. C., Eggenberger, N., Zito, G., Vanbellingen, T., Schumacher, R., Hopfner, S., Nyffeler, T., Gutbrod, K., 1890

1] Annoni, J. M., Bohlhalter, S., \& Muri, R. M. (2015). Perception of co-speech gestures in aphasic patients: a visual exploration study during the observation of dyadic conversations. Cortex, 64, 157-68. doi 10.1016/j.cortex. 2014.10 .013

Prins, R., \& Bastiaanse, R. (2004). Review. Aphasiology, 18, 1075-1091.

Prutting, C., \& Kirchner, D. (1987). A clinical appraisal of the pragmatic aspects of language. Journal of Speech 1895 
Pulvermuller, F., \& Berthier, M. L. (2008). Aphasia therapy on a neuroscience basis. Aphasiology, 22, 563-599. doi $10.1080 / 02687030701612213$

Purdy, M. (2002). Executive function ability in persons with aphasia. Aphasiology, 16, 549-557. doi 10.1080/ 02687030244000176

Purdy, M., Duffy, R., \& Coelho, C. (1994). An invesitgation of the communicative use of trained symbols following multimodality training. Clinical Aphasiology, 22, 345-356.

Rabagliati, H., \& Robertson, A. (2017). How do children learn to avoid referential ambiguity? insights from eyetracking. Journal of Memory and Language, 94, 15-27. doi 10.1016/j.jml.2016.09.007

Ramsberger, G. (1994). Functional perspective for assessment and rehabilitation of persons with severe aphasia. In Seminars in Speech and Language (pp. 1-16). (C) 1994 by Thieme Medical Publishers, Inc. volume 15. doi 10. $1055 / \mathrm{s}-2008-1064130$

Ramsberger, G., \& Rende, B. (2002). Measuring transactional success in the conversation of people with aphasia. Aphasiology, 16, 337-353. doi 10.1080/02687040143000636

Rayner, H., \& Marshall, J. (2003). Training volunteers as conversation partners for people with aphasia. International Journal of Language \& Communication Disorders, 38, 149-164. doi 10.1080/1368282021000060308

Records, N. (1994). A measure of the contribution of a gesture to the perception of speech in listeners with aphasia. Journal of Speech, Language, and Hearing Research, 37, 1086-1099.

Renvall, K., Laine, M., Laakso, M., \& Martin, N. (2003). Anomia treatment with contextual priming: A case study. Aphasiology, 17, 305-328. doi https://doi.org/10.1080/729255461

Renvall, K., Laine, M., \& Martin, N. (2007). Treatment of anomia with contextual priming: Exploration of a modified 口 procedure with additional semantic and phonological tasks. Aphasiology, 21, 499-527. doi https://doi.org/10. $1080 / 02687030701254248$

Rhys, C. S., Ulbrich, C., \& Ordin, M. (2013). Adaptation to aphasia: grammar, prosody and interaction. Clin Linguist Phon, 27, 46-71. doi 10.3109/02699206.2012.736010.

Robinson, P. (1995). Task complexity and second language narrative discourse. Language Learning, 45, 99-140. doi https://doi.org/10.1111/j.1467-1770.1995.tb00964.x

Robinson, P., \& Gilabert, R. (2007). Task complexity, the cognition hypothesis and second language learning and performance. International Review of Applied Linguistics in Language Teaching, .

Roper, A., Marshall, J., \& Wilson, S. (2016). Benefits and limitations of computer gesture therapy for the rehabilitation of severe aphasia. Front Hum Neurosci, 10, 595. doi 10.3389/fnhum.2016.00595.

Rose, M., \& Douglas, J. (2003). Limb apraxia, pantomine, and lexical gesture in aphasic speakers: Preliminary findings. Aphasiology, 17, 453-464. doi 10.1080/02687030344000157 
Rose, M. L. (2006). The utility of arm and hand gestures in the treatment of aphasia. Advances in Speech Language Pathology, 8, 92-109. doi $10.1080 / 14417040600657948$

Roxbury, T., McMahon, K., \& Copland, D. (2014). An fmri study of concreteness effects in spoken word recognition. Behavioral and Brain Functions, 10. doi/https://doi.org/10.1186/1744-9081-10-34

Roxnagel, C. (2000). Cognitive load and perspective-taking: applying the automatic-controlled distinction to verbal

Rubin, R. D., Brown-Schmidt, S., Duff, M. C., Tranel, D., \& Cohen, N. J. (2011). How do i remember that i know you know that i know? Psychol Sci, 22, 1574-82. doi $10.1177 / 0956797611418245$

Rudd, T. (Ed.) (2016). National Clinical Guideline for Stroke. (5th ed.). Royal College of Physicians.

Sachs, J. (1983). Talking about the there and then: The emergence of displaced reference in parentchild discourse. In K. Nelson (Ed.), Children's language (pp. 1-28). Hillsdale, NJ: Erlbaum volume 4.

Sacks, H., Schegloff, E., \& Jefferson, G. (1974). A simplest systematics for the organization of turn-taking for conversation. Language, 50, 696-732. doi 10.2307/412243.

Saffran, E., \& Martin, N. (1997). Effects of structural priming on sentence production in aphasics. Language and Cognitive Processes, 12, 877-882. doi $10.1080 / 016909697386772$

Salomo, D., Graf, E., Lieven, E., \& Tomasello, M. (2011). The role of perceptual availability and discourse context in young children's question answering. J Child Lang, 38, 918-31. doi 10.1017/S0305000910000395.

Sampson, M., \& Faroqi-Shah, Y. (2011). Investigation of self-monitoring in fluent aphasia with jargon. Aphasiology, 25, 505-528. doi 10.1080/02687038.2010.523471. 
Samuelsson, C., \& Hyde, L. (2016). Collaboration, trouble and repair in multiparty interactions involving couples with dementia or aphasia. Int $J$ Speech Lang Pathol, 19, 454-464. doi 10.1080/17549507.2016.1221448

Sandberg, C., \& Kiran, S. (2014). Analysis of abstract and concrete word processing in persons with aphasia and agematched neurologically healthy adults using fMRI. Neurocase, 20, 361-388. doi 10.1080/13554794.2013.770881

Sanders, T. J., \& Gernsbacher, M. A. (2004). Accessibility in text and discourse processing. Discourse Process, 37, 79-89. doi 10.1207/s15326950dp3702_1

Sarno, M. (1969). The Functional Communication Profile.

Schegloff, E. (1982). Discourse as an interactional achievement: Some uses of 'uh huh' and other things that come between sentences. In D. Tannen (Ed.), Georgetown University Roundtable on Language and Linguistics. Analyzing Discourse: Text and Talk. Washington D.C.: Georgetown University Press.

Scherer, K. (1986). Vocal affect expression: A review and a model for future research. Psychological Bulletin, 99, 143-165. doi http://dx.doi.org/10.1037/0033-2909.99.2.143

Schlenck, K.-J., Huber, W., \& Willmes, K. (1987). Prepairs and repairs: Different monitoring functions in aphasic language production. Brain and Language, 30, 226-244. doi 10.1016/0093-934x(87)90100-3

Schmid, G., \& Ziegler, W. (2006). Audio-visual matching of speech and non-speech oral gestures in patients with aphasia and apraxia of speech. Neuropsychologia, 44, 546-55. doi 10.1016/j.neuropsychologia.2005.07.002

Schober, M. (1993). Spatial perspective-taking in conversation. Cognition, 47, 1-24. doi 10.1016/0010-0277(93) 90060-9

Schober, M., \& Brennan, S. (2003). Handbook of discourse processes. chapter Processes of interactive spoken discourse: The role of the partner. (pp. 123-164). Mahwah, NJ.: Lawrence Erlbaum Associates Publishers.

Schober, M., \& Clark, H. (1989). Understanding by addressees and overhearers. Cognitive Psychology, 21, 211-232. doi $10.1016 / 0010-0285(89) 90008-\mathrm{X}$

Schwanenflugel, P. J., Akin, C., \& Luh, W.-M. (1992). Context availability and the recall of abstract and concrete words. Memory \& Cognition, 20, 96-104. doi 10.3758/bf03208259

Seddoh, S. (2000). Basis of intonation disturbance in aphasia: Production. Aphasiology, 14, 1105-1126. doi 10. $1080 / 02687030050174656$

Seddoh, S. (2006). Basis of intonation disturbance in aphasia: Perception. Journal of Neurolinguistics, 19, 270-290. doi $10.1016 /$ j.jneuroling.2005.12.002

Sekine, K., \& Rose, M. L. (2013). The relationship of aphasia type and gesture production in people with aphasia. American Journal of Speech-Language Pathology, 22. doi 10.1044/1058-0360(2013/12-0030) 
Selting, M. (2005). Syntax and lexis in conversation: Studies on the use of linguistic resources in talk-in-interaction. chapter Syntax and prosody as methods for the construction and identification of turn-constructional units in conversation. (pp. 17-44). John Benjamins Publishing. doi https://doi.org/10.1075/sidag.17.04sel

Simmons, N. (1993). An Ethnographic Investigation of Compensatory Strategies in Aphasia. (Volumes I and II). Ph.D. thesis Louisiana State University and Agricultural \& Mechanical College.

Simmons-Mackie, N., \& Damico, J. S. (2001). Intervention outcomes: A clinical application of qualitative methods. Topics in Language Disorders, 22, 21-36.

Simmons-Mackie, N., Damico, J. S., \& Damico, H. L. (1999). A qualitative study of feedback in aphasia treatment. American Journal of Speech-Language Pathology, 8, 218-230.

Simmons-Mackie, N., Raymer, A., Armstrong, E., Holland, A., \& Cherney, L. R. (2010). Communication partner training in aphasia: a systematic review. Arch Phys Med Rehabil, 91, 1814-37. doi 10.1016/j.apmr.2010.08.026

Simmons-Mackie, N., Savage, M. C., \& Worrall, L. (2014). Conversation therapy for aphasia: a qualitative review of the literature. Int $J$ Lang Commun Disord, 49, 511-26. doi 10.1111/1460-6984.12097

Singer, M., \& Goldin-Meadow, S. (2005). Children learn when their teacher's gestures and speech differ. Psychological Science, 16, 85-89. doi 10.1111/j.0956-7976.2005.00786.x

Skipper, J. (2014). Echoes of the spoken past: how auditory cortex hears context during speech perception. Philosophical Transactions of the Royal Society of London. Series B, Biological Sciences, 369, 1-19. doi $10.1098 /$ rstb.2013.0297.

Smith, S. W., Noda, H. P., Andrews, S., \& Jucker, A. H. (2005). Setting the stage: How speakers prepare listeners 1 for the introduction of referents in dialogues and monologues. Journal of Pragmatics, 37, 1865-1895. doi 10. 1016/j.pragma.2005.02.016

Swaab, T., Brown, C., \& Hagoort, P. (1997). Spoken sentence comprehension in aphasia: Event-related potential

口 evidence for a lexical integration deficit. Journal of Cognitive Neuroscience, 9, 39-66. doi 10.1162/jocn.1997.9. 1.39

Swerts, M., \& Krahmer, E. (2005). Audiovisual prosody and feeling of knowing. Journal of Memory and Language, 2015 53, 81-94. doi $10.1016 / \mathrm{j} \cdot \mathrm{jml} .2005 .02 .003$

Swinney, D., Prather, P., \& Love, T. (2000). The time-course of lexical access and the role of context. In Language and the Brain (pp. 273-292). Elsevier. doi 10.1016/b978-012304260-6/50016-5

Tanenhaus, M., Spivey-Knowlton, M., Eberhard, K., \& Sedivy, J. (1995). Integration of visual and linguistic information in spoken language comprehension. Science, 268, 1632-1634. doi 10.1126/science.7777863 
Thompson, C., Worrall, L., \& Martin, N. (2008)
impairment and its consequences (pp. 3-24).

Tolins, J., \& Fox Tree, J. (2014). Addressee backchannels steer narrative development. Journal of Pragmatics, 70, 152-164. doi 10.1016/j.pragma.2014.06.006

Turner, S., \& Whitworth, A. (2006). Clinicians' perceptions of candidacy for conversation partner training in 2025

1 aphasia: How do we select candidates for therapy and do we get it right? Aphasiology, 20,616-643. doi 10.1080/ 02687030600687860 .

Ulmer, E., Hux, K., Brown, J., Nelms, T., \& Reeder, C. (2016). Using self-captured photographs to support the

घ expressive communication of people with aphasia. Aphasiology, 31, 1183-1204. doi 10.1080/02687038.2016. 1274872 .

Veinott, E., Olson, J., Olson, G., \& Fu, X. (1999). Video helps remote work: Speakers who need to negotiate common ground benefit from seeing each other. In CHI'99 (pp. 302-309).

Vigliocco, G., Perniss, P., \& Vinson, D. (2014). Language as a multimodal phenomenon: implications for language

口 learning, processing and evolution. Philos Trans R Soc Lond B Biol Sci, 369, 20130292. doi 10.1098/rstb.2013. 0292

Wagner, M., \& Watson, D. G. (2010). Experimental and theoretical advances in prosody: A review. Lang Cogn Process, 25, 905-945. doi 10.1080/01690961003589492.

Wakefield, E., Novack, M. A., Congdon, E. L., Franconeri, S., \& Goldin-Meadow, S. (2018). Gesture helps learners learn, but not merely by guiding their visual attention. Dev Sci, (p. e12664). doi 10.1111/desc.12664

Walker, J. P., Joseph, L., \& Goodman, J. (2009). The production of linguistic prosody in subjects with aphasia. Clin Linguist Phon, 23, 529-49. doi 10.1080/02699200902946944.

Walker, T., Thomson, J., \& Watt, I. (2016). Displays and claims of understanding in conversation by people with aphasia. Aphasiology, 30, 750-764. doi 10.1080/02687038.2015.1119797

Wall, K. J., Cumming, T. B., \& Copland, D. A. (2017). Determining the association between language and cognitive tests in poststroke aphasia. Frontiers in Neurology, 8. doi 10.3389/fneur.2017.00149.

Wallace, S., Worrall, L., Rose, T., Le Dorze, G., Breitenstein, C., Enderby, P., Bose, A., Brady, M., Cruice, M., Copland, D., Hersh, D., Cherney, L., Babbitt, E., Rochon, E., Pearl, G., Hilari, K., Marshall, J., Webster, J., Kelly, H., Howe, T., Kiran, S., Nicholas, M., Rose, M., Sage, K., Laska, A., Patterson, J., \& Small, S. (submitted). A core outcome set for aphasia treatment research: Consensus statement. International Journal of Stroke, .

Wallace, S. J., Worrall, L., Rose, T., \& Le Dorze, G. (2017). Which treatment outcomes are most important to 2050

aphasia clinicians and managers? an international e-delphi consensus study. Aphasiology, 31, 643-673. doi 10. $1080 / 02687038.2016 .1186265$ 
Wallace, S. J., Worrall, L., Rose, T., Le Dorze, G., Cruice, M., Isaksen, J., Kong, A. P. H., Simmons-Mackie, N., Scarinci, N., \& Gauvreau, C. A. (2016). Which outcomes are most important to people with aphasia and their families? an international nominal group technique study framed within the icf. Disabil Rehabil, 39, 1364-1379. doi $10.1080 / 09638288.2016 .1194899$

Warren, T., Dickey, M., \& Lei, C. (2016). Structural prediction in aphasia: Evidence from either. Journal of Neurolinguistics, 39, 38-48. doi 10.1016/j.jneuroling.2016.01.001

Webster, J., Whitworth, A., \& Morris, J. (2015). Is it time to stop "fishing"? a review of generalisation following aphasia intervention. Aphasiology, 29, 1240-1264. doi 10.1080/02687038.2015.1027169.

Weinrich, M., Boser, K., McCall, D., \& Bishop, V. (2001). Training agrammatic subjects on passive sentences:

1. Implications for syntactic deficit theories. Brain and Language, 76, 45-61. doi https://doi.org/10.1006/brln. 2000.2421

Wennerstrom, A. (2001). Intonation and evaluation in oral narratives. Journal of Pragrnatics, 33, 1183-1206. doi https://doi.org/10.1016/S0378-2166(00)00061-8

Westbury, C. (2011). Assessing language impairment in aphasia: Going beyond pencils and paper in the computer age volume 5. John Benjamins Publishing Company. doi $10.1075 / \mathrm{ml} .5 .3 .03 w e s$

Whitworth, A., Claessen, M., Leitao, S., \& Webster, J. (2015). Beyond narrative: Is there an implicit structure to

口 the way in which adults organise their discourse? Clin Linguist Phon, 29, 455-81. doi 10.3109/02699206.2015. 1020450

Wilkes-Gibbs, D., \& Clark, H. (1992). Coordinating beliefs in conversation. Journal of Memory and Language, 31, 183-194. doi https://doi.org/10.1016/0749-596X(92)90010-U

Wilkinson, R. (1995). Case studies in clinical linguistics. chapter Aphasia: conversation analysis of a non-fluent aphasic person.. (pp. 271-292). London: Whurr.

Wilkinson, R. (2015). Conversation and aphasia: Advances in analysis and intervention. Aphasiology, 29, 257-268. doi $10.1080 / 02687038.2014 .974138$

Wilkinson, R., Bryan, K., Lock, S., \& Sage, K. (2010). Implementing and evaluating aphasia therapy targeted at couples' conversations: A single case study. Aphasiology, 24, 869-886. doi 10.1080/02687030903501958

Wilkinson, R., \& Wielaert, S. (2012). Rehabilitation targeted at everyday communication: can we change the talk of people with aphasia and their significant others within conversation? Arch Phys Med Rehabil, 93, S70-6. doi $10.1016 /$ j.apmr.2011.07.206

Willems, R. (2015). Cognitive neuroscience of natural language use. chapter Introduction. (pp. 1-7). Cambridge University Press. 
Wirz, S. L., Skinner, \& Dean (1990). Revised Edinburgh Functional Communication Profile. Communication Skill Builders.

Witteman, J., van IJzendoorn, M., van de Velde, D., van Heuven, V., \& Schiller, N. (2011). The nature of hemispheric specialization for linguistic and emotional prosodic perception: a meta-analysis of the lesion literature. Neuropsychologia, 49, 3722-38. doi 10.1016/j.neuropsychologia.2011.09.028

Worrall, L. (2006). Professionalism and functional outcomes. J Commun Disord, 39, 320-7. doi 10.1016/j.jcomdis . 2006.02 .007

Yoon, S. O., Koh, S., \& Brown-Schmidt, S. (2012). Influence of perspective and goals on reference production in conversation. Psychonomic Bulletin \& Review, 19, 699-707. doi 10.3758/s13423-012-0262-6.

Yorkston, K., \& Beukelman, D. (1980). An analysis of connected speech samples of aphasic and normal speakers. Journal of Speech and Hearing Disorders, 45, 27-36.

Yorkston, K., Beukelman, D., \& Waugh, P. (1979). A comparison of verbal, pantomime and combined instruction 2095 modes with severely aphasic individuals. In Clinical Aphasiology Conference.

Youse, K. M., Cienkowski, K. M., \& Coelho, C. A. (2004). Auditory-visual speech perception in an adult with aphasia. Brain Inj, 18, 825-34. doi 10.1080/02699000410001671784

Zwaan, R. A. (2014). Embodiment and language comprehension: reframing the discussion. Trends Cogn Sci, 18, 229-34. doi $10.1016 / j . t i c s .2014 .02 .008$ 